\title{
Revision of Khawia spp. (Cestoda: Caryophyllidea), parasites of cyprinid fish, including a key to their identification and molecular phylogeny
}

\author{
Tomáš Scholz ${ }^{1}$, Jan Brabec ${ }^{1}$, Ivica Král'ová-Hromadová ${ }^{2}$, Mikuláš Oros $^{2}$, Eva Bazsalovicsová2 \\ Alexey Ermolenko ${ }^{3}$ and Vladimíra Hanzelová ${ }^{2}$
}

\author{
${ }^{1}$ Institute of Parasitology, Biology Centre of the Academy of Sciences of the Czech Republic, and Faculty of Science, \\ University of South Bohemia, Branišovská 31, 37005 České Budějovice, Czech Republic; \\ ${ }^{2}$ Parasitological Institute, Slovak Academy of Sciences, Hlinkova 3, 04001 Košice, Slovak Republic; \\ ${ }^{3}$ Institute of Biology and Soil Science, Far Eastern Branch of Russian Academy of Sciences, Vladivostok, Russia
}

\begin{abstract}
Monozoic cestodes of the genus Khawia Hsü, 1935 (Caryophyllidea: Lytocestidae), parasites of cyprinid fish in Europe, Asia, Africa and North America, are revised on the basis of taxonomic evaluation of extensive materials, including recently collected specimens of most species. This evaluation has made it possible to critically assess the validity of all 17 nominal species of the genus and to provide redescriptions of the following seven species considered to be valid: Khawia sinensis Hsü, 1935 (type species); K. armeniaca (Cholodkovsky, 1915); K. baltica Szidat, 1941; K. japonensis (Yamaguti, 1934); K. parva (Zmeev, 1936); K. rossittensis (Szidat, 1937); and K. saurogobii Xi, Oros, Wang, Wu, Gao et Nie, 2009. Several new synonyms are proposed: Khawia barbi Rahemo et Mohammad, 2002 and K. lutei Al-Kalak et Rahemo, 2003 are synonymized with K. armeniaca; K. coregoni Kritscher, 1990 with Caryophyllaeus laticeps (Pallas, 1781) (family Caryophyllaeidae); K. cyprini Li, 1964 and K. iowensis Calentine et Ulmer, 1961 with K. japonensis; K. dubia (Szidat, 1937) (syn. Bothrioscolex dubius Szidat, 1937) with K. rossittensis; and Tsengia neimongkuensis Li, 1964 and T. xiamenensis Liu, Yang et Lin, 1995 with K. sinensis. Khawia prussica (Szidat, 1937) (syn. Bothrioscolex prussicus Szidat, 1937) is considered to be species incertae sedis, but its morphology indicates it may belong to Caryophyllaeus Gmelin, 1790 (Caryophyllaeidae). The molecular analysis of all seven valid species, based on comparison of sequences of two nuclear ribosomal and two mitochondrial genes, has shown that the species form three major groups clustered according to their fish hosts. Five species from common and crucian carp and goldfish were grouped together, whereas K. armeniaca from barbels (Barbinae) and K. baltica from tench (Tinca) formed separate clades. In contrast, geographical distribution does not seem to play a crucial role in grouping of individual taxa. A phylogenetic tree based on morphological characters was incongruent with that inferred from molecular data, which indicates that some morphological traits may be homoplastic. A key to identification of all species of Khawia based on morphological characteristics is provided.
\end{abstract}

Keywords: tapeworms, freshwater fish, comparative morphology, taxonomy, phylogenetic relationships, identification, DNA sequences, Holarctic Region

Tapeworms of the order Caryophyllidea van Beneden in Carus, 1863 are monopleuroid, i.e., their body is monozoic and contains, unlike all other "true" cestodes (Eucestoda), only one set of genital organs (Mackiewicz 1981a, 1994). About 230 nominal species have been described from the intestine of cypriniform and siluriform fish in the Holarctic, Ethiopian, Indomalayan and Australian zoogeographical regions (Schmidt 1986).

One of the most specious genera of the order, Khawia Hsü, 1935, was erected by Hsü (1935) to accommodate the new species, Khawia sinensis, from the intestine of common carp (Cyprinus carpio L.) from the vicinity of Peking (Beijing) in China. Since that time, as many as 16 other species have been placed in the genus (Li 1964,
Mackiewicz 1972, Schmidt 1986, Kritscher 1990, Rahemo and Mohammad 2002, Al-Kalak and Rahemo 2003, Yang 2007, Xi et al. 2009a), including three taxa described originally by Szidat (1937) as members of Bothrioscolex Szidat, 1937, which was first synonymized with Khawia by Markevich (1951).

Until now, relatively extensive data on the morphology and life cycles of several species of Khawia have been provided (e.g., Kulakovskaya 1961, 1962, 1963, 1964, Dubinina 1971, 1987, Demshin 1975, 1978, 1984, Demshin and Dvoryadkin 1980, Scholz 1989, 1991a, b, Protasova et al. 1990, Scholz et al. 2001, Oros and Hanzelová 2007). However, the taxonomic status of some taxa, especially those described from China and Iraq, is

Address for correspondence: T. Scholz, Institute of Parasitology, Biology Centre of the Academy of Sciences of the Czech Republic, Branišovská 31, 37005 České Budějovice, Czech Republic. Phone: +420 38 5310351; Fax:+420 38 5310388; E-mail: tscholz@paru.cas.cz 
not clear, and neither are their phylogenetic relationships. The species composition of the genus and validity of individual species have not been critically reviewed yet.

In this paper, the genus is revised on the basis of the evaluation of extensive, usually newly collected materials of most nominal species (types of very few species were available). In addition, molecular markers (DNA sequences of two mitochondrial and two nuclear genes) were used for assessment of phylogenetic relationships of individual species.

\section{MATERIALS AND METHODS}

\section{Materials}

Material of the following species was studied (numbers of specimens studied, their hosts, geographical origin, sampling dates and names of collectors are given in redescriptions of individual species, together with collection numbers): Khawia sinensis Hsü, 1935 (type species); K. armeniaca (Cholodkovsky, 1915); K. baltica Szidat, 1941; K. coregoni Kritscher, 1990; $K$. iowensis Calentine et Ulmer, 1961; K. japonensis (Yamaguti, 1934); K. parva (Zmeev, 1936); K. rossittensis (Szidat, 1937); and K. saurogobii Xi, Oros, Wang, Wu, Gao et Nie, 2009.

No material of $K$. dubia (Szidat, 1937) (syn. Bothrioscolex dubius Szidat, 1937) and K. prussica (Szidat, 1937) (syn. Bothrioscolex prussicus Szidat, 1937) was available. The species have never been found since their original descriptions. Type or voucher specimens of $K$. barbi Rahemo et Mohammad, 2002 and $K$. lutei Al-Kalak et Rahemo, 2003, both described from Carasobarbus luteus (Heckel) from Iraq, were also not available, despite repeated requests to the authors of these species for loans. However, Khawia specimens from two barbels, Barbus barbulus Heckel and B. grypus Heckel, from Iraq were studied. Similarly, type or voucher specimens of four species described from common carp from China, namely Khawia cyprini Li, 1964, Khawia tenuicollis $\mathrm{Li}, 1964$, Tsengia neimongkuensis $\mathrm{Li}$, 1964 (= Khawia neimongkuensis) and Tsengia xiamenensis Liu, Yang et Lin, 1995 (= Khawia xiamenensis), were not available despite several requests to Chinese authors and they are not known to exist.

\section{Morphology, histology and scanning electron microscopical (SEM) observations}

Tapeworms collected recently were processed using the methods described by de Chambrier et al. (2008) and Oros et al. (2010). Fish hosts were examined immediately after their capture and live tapeworms were isolated from the host intestine, rinsed in saline and placed into a beaker or a vial with a small amount of saline. Hot (almost boiling) 4\% neutral buffered formaldehyde solution (= formalin) was added to the beaker or vial as soon as possible. This fixation method provides the best material of fish cestodes for comparative studies (see Appendix in Oros et al. 2010) because it ensures that the worms remain straight and are not unnaturally contracted or deformed. After 2-3 weeks, tapeworms were transferred to $70 \%$ ethanol before further processing.

The specimens were stained with Mayer's hydrochloric carmine solution as described by Scholz and Hanzelová (1998). For histological sections, pieces of worms were embedded in paraffin wax, sectioned at $12-15 \mu \mathrm{m}$, stained with Weigert's haematoxylin, and counterstained with $1 \%$ eosin B with one drop of acetic acid/100 $\mathrm{ml}$ of solution (de Chambrier 2001).
Line drawings were made using a drawing attachment of an Olympus BX51 microscope with the use of Nomarski interference contrast. Measurements were taken using Olympus QuickPhoto MICRO 2.1 programme. All measurements are given in micrometres unless otherwise indicated.

Scanning electron micrographs of all but one (K. parva) species have recently been published by Oros et al. $(2010$ - fig. $1 \mathrm{~K}-\mathrm{Q}$ ), but the specimen of $K$. baltica was fixed with cold formalin, which caused its unnatural contraction (fig. $1 \mathrm{~L}$ in Oros et al. 2010). Therefore, recently collected specimens of this species, fixed with hot formalin, were used for SEM observations, together with the scolex of K. parva, which was fixed with $96 \%$ ethanol for DNA sequencing. The specimens were dehydrated through a graded ethanol series, followed by a graded amyl acetate series, dried by critical-point method, sputter-coated with 20-25 nm of gold and examined with a JEOL JSEM 7401F microscope (see Oros et al. 2010).

\section{Deposition of specimens}

Specimens studied are deposited in the helminthological collection of the Institute of Parasitology, Biology Centre of the Academy of Sciences of the Czech Republic, České Budějovice, Czech Republic (acronym IPCAS); The Natural History Museum, London, UK (BMNH); East-Slovakian Museum, Košice, Slovakia (ESMK); collection of the former Helminthological Laboratory of the Russian Academy of Sciences, Moscow, Russia (now Parasitology Centre of the Institute of Ecological and Evolutionary Problems - acronym GELAN); Natural History Museum, Geneva, Switzerland (MHNG); Meguro Parasitological Museum, Tokyo, Japan (MPM); Natural History Museum, Vienna, Austria (NHMW); Parasitological Institute, Slovak Academy of Sciences, Košice, Slovakia (PISAS); U.S. National Parasite Collection, Beltsville, Maryland, USA (USNPC); and Zoological Institute of the Russian Academy of Sciences, Sankt Petersburg, Russia (ZIRAS).

\section{DNA isolation, PCR and sequencing protocols}

Seven recognized Khawia species (eleven samples; for details see Table 1), preserved in $96 \%$ ethanol, were analyzed molecularly. Prior to molecular studies, each specimen was identified on the basis of morphological characteristics. The genomic DNA was isolated using QIAamp ${ }^{\circledR}$ DNA Kit (QIAGEN, Hilden, Germany). For phylogenetic studies, nuclear ribosomal (complete small subunit, ssrDNA, 1,571-1,655 bp, and partial large subunit, D1-D3 1srDNA, 2,100-2,104 bp) and mitochondrial (complete nicotinamide dehydrogenase subunit III, nad3, $345 \mathrm{bp}$, and partial cytochrome $c$ oxidase subunit I, cox 1,672 675 bp) genes were amplified using PCR conditions described previously by Littlewood et al. (2008) and Králová-Hromadová et al. (2010), respectively. Table 2 shows details on primers employed for PCR amplification and sequencing of desired ribosomal and mitochondrial genes. The originally designed CFCYT1 primer annealed in the tRNA gene for isoleucine and was applied for amplification of complete mitochondrial nad3. The PCR products were loaded on $1.5 \%$ agarose gel and purified using Wizard PCR purification Kit (Promega, Madison, Wisconsin, USA). Purified PCR products were directly sequenced using Applied Biosystems 3130xl automatic DNA analyzer and BigDye Terminator v3.1 Cycle sequencing kit (Applied Biosystems, Foster City, California, USA).

\section{Phylogenetic analyses of molecular data}

The mitochondrial nad 3 and $\operatorname{cox} 1$ and the nuclear ssrDNA and lsrDNA sequences were assembled and aligned using Ge- 
Table 1. Hosts and geographical origin of Khawia species analyzed molecularly in the present study. The ribosomal and mitochondrial sequences are deposited in the GenBank database under accession numbers indicated herein.

\begin{tabular}{|c|c|c|c|c|}
\hline Khawia species & Fish host & Locality & $\begin{array}{l}\text { Accession number } \\
\text { ssrDNA/lsrDNA }\end{array}$ & $\begin{array}{l}\text { Accession number } \\
\text { nad } 3 / \text { cox } 1\end{array}$ \\
\hline K. armeniaca & Coregonus lavaretus $^{1}$ & Lake Sevan, Armenia & JN004246/JN004257 & JN004235/JN004224 \\
\hline Khawia sp. ${ }^{2}$ & Luciobarbus bocagei & Este River, Porto, Portugal & JN004252/JN004263 & JN004241/JN004230 \\
\hline K. baltica & Tinca tinca & Nové Hrady, Czech Republic & JN004255/JN004266 & JN004244/JN004233 \\
\hline K. japonensis & Cyprinus carpio & Lake Oonuma, Hokkaido, Japan & JN004247/JN004258 & JN004236/JN004225 \\
\hline$K$. parva & Carassius gibelio & Lake Khanka, Primorye, Russia & JN004256/JN004267 & JN004245/JN004234 \\
\hline K. rossittensis & Carassius auratus & Tisa River, Slovakia & JN004249/JN004260 & JN004238/JN004227 \\
\hline K. rossittensis & Carassius auratus & Lake Biwa, Japan & JN004248/JN004259 & JN004237/JN004226 \\
\hline K. saurogobii & Saurogobio dabryi & Yangtze River, Wuhan, China & JN004251/JN004262 & JN004240/JN004229 \\
\hline K. sinensis & Cyprinus carpio & Latorica River, Slovakia & JN004250/JN004261 & JN004239/JN004228 \\
\hline K. sinensis & Cyprinus carpio & Lake Dong-Hu, Wuhan, China & JN004254/JN004265 & JN004243/JN004232 \\
\hline K. sinensis & Cyprinus carpio & Lake Biwa, Japan & JN004253/JN004264 & JN004242/JN004231 \\
\hline
\end{tabular}

'Probably atypical host; ${ }^{2}$ Based on its morphology, the specimen is considered to be conspecific with $K$. armeniaca (see the text).

Table 2. Primers applied in amplification and sequencing of complete ssrDNA and D1-D3 1srDNA, and complete nad3 and partial cox 1 mitochondrial genes.

\begin{tabular}{llll}
\hline Primer & Sequence $\left(5^{\prime}-3^{\prime}\right)$ & Application & Reference \\
\hline WormA & GCGAATGGCTCATTAAATCAG & PCR amplification of ssrDNA & Littlewood and Olson 2001 \\
WormB & CTTGTTACGACTTTACTTCC & PCR amplification of ssrDNA & Littlewood and Olson 2001 \\
600F & GGTGCCAGCAGCCGCG & Internal ssrDNA primer & Littlewood and Olson 2001 \\
600R & ACCGCGGCTGCTGGCACC & Internal ssrDNA primer & Littlewood and Olson 2001 \\
1600F & CAGGTCTGTGATGCCC & Internal ssrDNA primer & Littlewood and Olson 2001 \\
1600R & GGGCATCACAGACCTG & Internal ssrDNA primer & Littlewood and Olson 2001 \\
LSU5 & TAGGTCGACCCGCTGAAYTTAAGC PCR amplification of lsrDNA & Littlewood et al. 2000 \\
1500R & GCTATCCTGAGGGAAACTTCG & PCR amplification of lsrDNA & Olson et al. 2003 \\
300F & CAAGTACCGTGAGGGAAAGTTG & Internal lsrDNA primer & Littlewood et al. 2000 \\
400R & GCAGCTTGACTACACCCG & Internal lsrDNA primer & Olson et al. 2003 \\
900F & CCGTCTTGAAACACGGACCAAG & Internal lsrDNA primer & Olson et al. 2003 \\
ECD2 & CTTGGTCCGTGTTTCAAGACGGG & Internal lsrDNA primer & Littlewood et al. 2000 \\
CFCYT1 & GCAGGTTACTTTGATATAG & PCR amplification of nad3+cox1 & present paper \\
CFCYT2 & ACTAAGTGTTTTCAAAA & PCR amplification cox1 & Bazsalovicsová et al. 2011 \\
CRCYT2 & CCAAAAAACCAAAACAT & PCR amplification $n a d 3+c o x 1$ & Bazsalovicsová et al. 2011 \\
\hline
\end{tabular}

neious Pro 5.1.6 (Drummond et al. 2009). The MAFFT G-INS-i algorithm was used while aligning individual genes and in case of nad 3 and cox 1 genes translational alignment was employed in order to respect the encoded amino acids. In case of ssrDNA and lsrDNA alignments, the ambiguously aligned positions were excluded from any subsequent phylogenetic analyses. The phylogenetic relationships within Khawia based on molecular data were evaluated using maximum likelihood criterion in the program RAxML version 7.2.8-ALPHA using the GTR $+\Gamma$ model. All model parameters and the bootstrap values were estimated by RAxML. Nucleotide alignments of nuclear ribosomal genes were analysed as a concatenated dataset of two independent partitions representing the ssrDNA and lsrDNA parts, for which individual parameters of the GTR $+\Gamma$ model were estimated. To test the severity of substitution saturation within the individual codon positions of nad 3 and $\operatorname{cox} 1$ alignments, we used the test of Xia et al. (2003) as implemented in DAMBE (Xia and Xie 2001). The third codon positions in both genes were found to be saturated and thus excluded from subsequent phylogenetic analyses.

Nucleotide and amino acid alignments of the two mitochondrial genes were also analysed as a concatenated dataset of two partitions. Here we let RAxML to estimate different model parameters for each codon positions within each of the nucleotide
Table 3. A numerical matrix of morphological characters and their coding for 7 species of Khawia and Caryophyllaeus laticeps (outgroup).

\begin{tabular}{lccccccccccc}
\hline Species/character & 1 & 2 & 3 & 4 & 5 & 6 & 7 & 8 & 9 & 10 & 11 \\
\hline Caryophyllaeus laticeps & 0 & 0 & 0 & 0 & 0 & 0 & 0 & 0 & 0 & 0 & 0 \\
Khawia armeniaca & 2 & 1 & 1 & 0 & 0 & 0 & 0 & 0,1 & 0 & 0 & 0 \\
Khawia baltica & 0 & 0 & 0 & 0 & 0 & 0 & 0 & 1 & 1 & 1 & 0 \\
Khawia japonensis & 1 & 2 & 0 & 1 & 0 & 1 & 1 & 1 & 0,1 & 1 & 1 \\
Khawia parva & 0 & 1 & 1 & 0 & 1 & 0 & 0 & 1 & 0 & 1 & 1 \\
Khawia rossittensis & 2 & 1,2 & 1 & 0 & 1 & 1 & 0 & 0,1 & 0 & 1 & 1 \\
Khawia saurogobii & 1 & 0 & 1 & 0 & 1 & 1 & 1 & 0 & 0 & 1 & 0 \\
Khawia sinensis & 0 & 0 & 0 & 1 & 1 & 0 & 0 & 0 & 0 & 1 & 1 \\
\hline
\end{tabular}

nad 3 and cox 1 alignments. The MtZoa amino acid substitution model (Rota-Stabelli et al. 2009) with $\Gamma$ model of rate heterogeneity was employed for analysis of the amino acid alignment of mitochondrial genes. Additionally, the nuclear ribosomal and mitochondrial data of seven Khawia species were analyzed as one concatenated dataset under the conditions described above.

\section{Phylogenetic analysis of morphological characters}

Interrelationships of Khawia species were also assessed using 11 morphological characters (see Appendix and Table 3). 
Caryophyllaeus laticeps (Pallas, 1781), a common parasite of cyprinid fish in the Palaearctic Region (see Scholz 1989 and Protasova et al. 1990 for data on its morphology), was used as outgroup because this species formed a sister group to a clade comprising $K$. sinensis in a most recent molecular study of interrelationships of caryophyllidean cestodes (Olson et al. 2008).

Phylogenetic analyses were performed using the maximum parsimony in program PAUP* Version $4.0 \mathrm{~b} 10$ for 32-bit Microsoft Windows (Swofford 2002). Characters were analysed as unordered, unweighted and their states optimised using the criterion of accelerated transformation (ACCTRAN). For maximum parsimony, 30 random addition sequence replicates of a heuristic search, using the tree bissection reconnection (TBR) algorithm, were performed. The results are presented as a $50 \%$ majority rule consensus tree. The cladogram topology was visualised using TreeView (Page 1996).

\section{RESULTS}

The following seven species of Khawia, rather than 17 nominal taxa, are considered to be valid: Khawia sinensis Hsü, 1935 (type species); K. armeniaca (Cholodkovsky, 1915); K. baltica Szidat, 1941; K. japonensis (Yamaguti, 1934); K. parva (Zmeev, 1936); K. rossittensis (Szidat, 1937); and K. saurogobii Xi, Oros, Wang, Wu, Gao et Nie, 2009. A survey of these species with their redescriptions and data on definitive hosts, geographical distribution and life cycles are provided below.

Numerous new synonyms are proposed: Khawia barbi Rahemo et Mohammad, 2002 and Khawia lutei Al-Kalak et Rahemo, 2003, both parasitic in Carasobarbus luteus (Heckel) in Iraq, are newly synonymized with $K$. armeniaca; Khawia coregoni Kritscher, 1990 from Coregonus wartmanni (Bloch) from Austria with Caryophyllaeus laticeps (Pallas, 1781) (family Caryophyllaeidae); Khawia cyprini Li, 1964 from Cyprinus carpio from China and Khawia iowensis Calentine et Ulmer, 1961 from the same host from North America with K. japonensis; K. dubia (Szidat, 1937) (syn. Bothrioscolex dubius Szidat, 1937) from Carassius carassius (L.) from East Prussia (now the Kaliningrad enclave of Russia) with $K$. rossittensis; and Tsengia neimongkuensis Li, 1964 and Tsengia xiamenensis Liu, Yang et Lin, 1995, both from C. carpio from China, with Khawia sinensis [Tsengia Li, 1964 was already synonymized with Khawia by Mackiewicz (1994), but he did not synonymize formally its species].

Khawia tenuicollis Li, 1964, described from common carp in China, has been recently transferred to Atractolytocestus Anthony, 1958 as a new combination by Xi et al. (2009b). Khawia prussica (Szidat, 1937) (syn. Bothrioscolex prussicus Szidat, 1937) from C. carassius from East Prussia is considered to be species incertae sedis because cross section of this species, which has never been found since its original description, are not available. However, morphology of this species, especially a short extent of preovarian uterine loops and a short ovarian region, indicates that it may belong to Caryophyllaeus Gmelin, 1790 (Caryophyllaeidae).

\section{Diagnosis of Khawia Hsü, 1935}

Synonyms: Bothrioscolex Szidat, 1937; Tsengia Li, 1964.

Diagnosis: Caryophyllidea, Lytocestidae, with characters of family, i.e., vitelline follicles cortical. Scolex flat, lacking apical structures and lateral loculi (afossate), variable in shape (see Oros et al. 2010). Anterior margin of scolex usually smooth, in some species frilled, festoon-like or with superficial longitudinal grooves. Testes medullary, numerous, reaching posteriorly to cirrus-sac. Cirrus-sac well developed, posteroventrally opening by male genital pore. Internal and external seminal vesicles absent. Ovary medullary, usually H-shaped, rarely inverted A-shaped. Seminal receptacle present. Vitelline follicles extensive, usually separated to preovarian and postovarian groups of follicles; a few follicles may be present alongside preovarian loops of uterus or alongside ovarian arms. Uterus never extends anterior to cirrus-sac. Uterine glands present. Eggs operculate, without fully developed oncospheres in utero. Male and female genital pores separate, open into genital atrium. Parasites of cyprinid fish (Cypriniformes: Cyprinidae). Eurasia, Africa and North America. Type species: Khawia sinensis Hsü, 1935.

Comments: Hsü (1935) proposed Khawia to accommodate his new species, Khawia sinensis Hsü, 1935. In addition to the type species, Hsü (1935) placed Caryophyllaeus japonensis Yamaguti, 1934 to this new genus based on the cortical position of preovarian vitelline follicles (a feature typical of the subfamily Lytocestinae Hunter, 1927, later raised to the family rank by Wardle and McLeod 1952) and a general resemblance of both species, including scolex shape and distribution of genital organs.

Markevich (1951) (not Fotedar [1958] as claimed by Yamaguti [1959] and subsequent authors) first synonymized Bothrioscolex Szidat, 1937 with Khawia, which implies that its species, namely B. dubius Szidat, 1937, B. prussicus Szidat, 1937 and B. rossittensis Szidat, 1937, are placed in the latter genus. This taxonomic action has been widely accepted (Yamaguti 1959, Schmidt 1986, Mackiewicz 1994) and Bothrioscolex is also here considered to be a junior synonym of Khawia. Another genus, Tsengia Li, 1964, was erected to accommodate Tsengia neimongkuensis Li, 1964 from common carp from Lake Wulasuhai in Inner Mongolia, China (Li 1964), but it was synonymized with Khawia by Mackiewicz (1994).

\section{Redescriptions of valid species of Khawia}

Khawia sinensis Hsü 1935 - type species Fig. 1 Synonyms (both new): Tsengia neimongkuensis Li, 1964; Tsengia xiamenensis Liu, Yang et Lin, 1995.

Material examined: One specimen from Yelabuga River, Far East, Russia, vi. 1958 (GELAN - no collection number); nine spec. from Lohja, Finland, xi. 1982 (E.T. Valtonen; BMNH 1983.10.10.30-41); 312 spec. from fishponds in South Bohemia, Czech Republic, 1984-1989 (T. Scholz; IPCAS C-46/1); six spec. from 


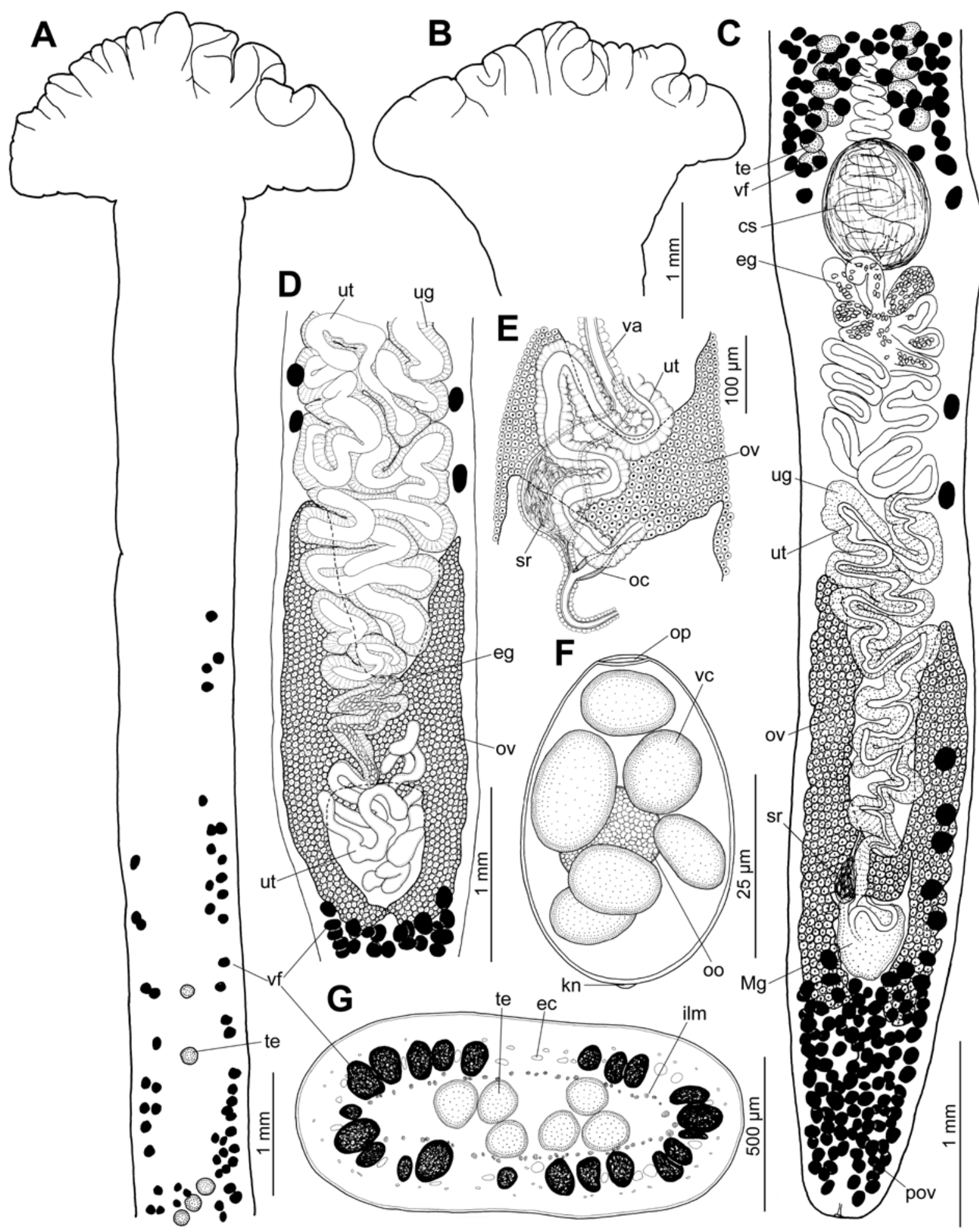

Fig. 1. Khawia sinensis Hsü, 1935 from Cyprinus carpio, Czech Republic (A, B, E, G) and Japan (C, F) (IPCAS C-46/1), and from Hemibarbus barbus, Japan (D) (IPCAS C-46/5). A - anterior part of the body (note a long distance of the anteriormost vitelline follicles and testes from the anterior extremity); B - scolex; C - posterior part of the body, dorsal (note asymmetrical distribution of vitelline follicles alongside the uterus and ovary - present on the dextral side whereas absent sinistrally); D - posterior end with inverted A-shaped ovary, dorsal; E - ovarian isthmus (bridge) with seminal receptacle, dorsal; F - egg (note operculum and knob on adopercular pole); $\mathbf{G}$ - cross section at the level of testes (note numerous longitudinal excretory canals in the cortex). Abbreviations: cs - cirrus-sac; ec - excretory canals; eg - eggs; ilm - inner longitudinal musculature; kn - adopercular knob; Mg - Mehlis' gland; oc - oocapt; oo - oocyte; op - operculum; ov - ovary; pov - postovarian vitelline follicles; sr - seminal receptacle; te - testes; ug - uterine glands; ut - uterus; va - vagina; vc - vitelline cells; vf - vitelline follicles. 
Novi Sad, Serbia, 1986 (IPCAS C-461); five spec. from England, xii. 1986 (R. Sweeting; BMNH 1987.2.4.1-4 and 1998.1.22.1); four spec. from England (W. Yeomans; BMNH 1991.7.1.87-91); five spec. from Austria (R. Konecny; BMNH 1991.7.1.34-35); 25 spec. from Lake Biwa, Japan, v. 1992 (T. Shimazu), v. 2001 (T. Scholz) and iv. 2007 (T. Scholz and R. Kuchta), and Aqua Restoration Research Centre, Gifu, Gifu Pref., Japan, iv. 2007 (T. Scholz and R. Kuchta; all IPCAS C-46/1); four spec. from Munich, Germany (E.T. Valtonen; BMNH 1995.2.13.501-503); one spec. from England, 2005 (C. Williams; BMNH 2005.10.5.14); 20 spec. from Ružín reservoir and the Latorica River, Slovakia (see Oros et al. 2009; PISAS 53/09 1-10); all specimens from Cyprinus carpio L. In addition, the following material from Hemibarbus barbus (Temminck et Schlegel) was examined: two spec. from the Hiroi River, Iyama, Japan, x. 1995 (T. Shimazu); one spec. from Lake Biwa at Moriyama, Japan, v. 1992 (T. Shimazu; see Scholz et al. 2001; BMNH 2001.1.26.4-5 and IPCAS C-46/5); five spec. from Lake Biwa at Momose, Japan, iv. 2007 (T. Scholz and R. Kuchta; IPCAS C-46/5).

Diagnosis (based on Oros et al. 2009; $\mathrm{n}=10$ ): Body large, 41-112 mm long; maximum width $1.3-2.3 \mathrm{~mm}$. Scolex festoon-like, with deep (up to $0.6 \mathrm{~mm}$ long) folds, mostly 7-12 in number, on anterior margin (front edge), wider than neck, $2.0-2.4 \mathrm{~mm}$ wide. Neck 0.7-1.1 mm wide. Testes numerous, estimated number (testes difficult to count, because numerous vitelline follicles form compact field, filling cortex and overlapping testes) 450-750 $(\mathrm{n}=4)$, oval, 159-179 × 128-163, medullary, beginning $3.0-9.5 \mathrm{~mm}$ from anterior extremity, $0.1-2.4 \mathrm{~mm}$ posterior to first vitelline follicles, reaching up to anterior margin of cirrus-sac. Cirrus-sac oval to almost spherical, thickwalled, $0.7-1.0 \times 0.5-0.7 \mathrm{~mm}$. Ovary bilobed, H-shaped, total width $1.1-2.1 \mathrm{~mm}$; lateral arms $2.2-4.1 \mathrm{~mm}$ long and $0.20-0.55 \mathrm{~mm}$ wide; anterior arms usually longer and wider than posterior ones, which may be bent inwards to touch each other. Vagina tubular, nearly straight, proximally joining with uterus to form uterovaginal canal that opens into genital atrium. Seminal receptacle dorsal to ovarian isthmus, $310-473 \times 130-270$. Vitelline follicles oval, 116-133 × 93-108, start anterior to first testes, 1.9$6.3 \mathrm{~mm}$ from anterior extremity, reach posteriorly alongside cirrus-sac up to anteriormost uterine coils. A few (2-15) follicles alongside preovarian uterine loops. Preovarian follicles cortical, postovarian follicles extensive, usually cortical, with some follicles in medulla (fig. 11 in Hsü 1935). Uterus sinuous. Eggs oval, operculate, unembryonated, 48-51 $\times 28-31(\mathrm{n}=30$, intrauterine eggs $)$ and 40-45 × 28-30 (freshly laid eggs - Scholz 1991b).

Ty pe host: Common carp, Cyprinus carpio L. (Cyprinidae: Cyprininae).

Type locality: "Peiping" (= Beijing), China.

Tyре specimens: Not available, not known to exist.
Definitive hosts*: Ctenopharyngodon idella (Valenciennes), *Cyprinus carpio, ${ }^{*}$ Hemibarbus barbus.

Life cycle: Kulakovskaya (1962, 1963), Demshin and Dvoryadkin (1980) and Scholz (1991a, b) studied experimentally life cycle, which is mainly controlled by temperature. Eggs are laid unembryonated into water and the oncosphere infective for intermediate hosts is formed after 2-4 weeks of embryonation within the egg shell at the temperature above $20^{\circ} \mathrm{C}$. Infective oncospheres survive about 2-3 months (Kulakovskaya 1962, Demshin and Dvoryadkin 1980, Scholz 1991b).

The following tubificids (Annelida: Oligochaeta) have been reported as intermediate hosts of $K$. sinensis under natural and/or laboratory conditions: Tubifex tubifex (Müller), Limnodrilus hoffmeisteri Claparède, L. udekemianus Claparède, Ilyodrilus templetoni (Southern), Potamothrix hammoniensis (Michaelsen) and Psammoryctides barbatus (Grube) (Kulakovskaya 1963, Demshin and Dvoryadkin 1980, Scholz et al. 1990, Scholz 1991b). The development of metacestodes (plerocercoids according to Chervy 2002) in intermediate hosts is completed after 8-9 weeks at $20-22^{\circ} \mathrm{C}$ (Demshin and Dvoryadkin 1980, Scholz 1991b). Metacestodes of K. sinensis have been proven to survive in tubificid hosts over winter even in emptied fishponds (Scholz et al. 1990).

The development of $K$. sinensis in experimental definitive host, common carp, takes $2.5-3$ months at $15-16^{\circ} \mathrm{C}$ (Scholz 1991a). Kulakovskaya (1962, 1963) estimated the prepatent period of the parasite in naturally infected populations of carp to last 4-6 months, but Shcherban (1965) reported a much shorter time (1.5-2 months).

Distribution: Asia (China and Russian Far East probably original distribution area; Japan - imported in 1975, Kazakhstan, Russia - Siberia, Turkmenistan, Uzbekistan), Europe (Austria†, Belorussia, Bosnia and Herzegovina, Bulgaria, Czech Republic, Finland $\dagger$, Germany, Great Britain, Hungary, Latvia, Lithuania, Moldavia, Poland, Romania, Russia, Serbia $\dagger$, Slovakia, Ukraine - all imported), North America (Oregon, USA - imported in 1975) (Oros et al. 2009, present study).

Remarks. Khawia sinensis was described by Hsü (1935) from tapeworms found in common carp (Cyprinus carpio) in China. The original description was detailed, but the scolex, which is one of the most typical characteristics of the species (see Oros et al. 2010), was not illustrated.

Li (1964) proposed a new genus, Tsengia, to accommodate his new species, T. neimongkuensis, from common carp from Lake Wulasuhai in China, but the genus was synonymized with Khawia by Mackiewicz (1994). Li (1964) did not compare his new species with any species of Khawia because of the possession of an inverted

* Records confirmed by the present authors are marked with an asterisk $\dagger$ New geographical records based on voucher specimens of $K$. sinensis deposited in collections (see list of the material examined), not reported by Oros et al. (2009) 
Table 4. Selected measurements (in millimetres unless otherwise stated) of Khawia armeniaca (Cholodkovsky, 1915) from different hosts and regions (collection numbers - see text). Extreme values for the species are in bold".

\begin{tabular}{|c|c|c|c|c|c|c|c|c|c|c|c|c|}
\hline Host & Country & $\begin{array}{l}\text { Total } \\
\text { length }\end{array}$ & $\begin{array}{l}\text { Maximum } \\
\text { width }\end{array}$ & $\begin{array}{l}\text { Scolex } \\
\text { width }\end{array}$ & $\begin{array}{l}\text { Neck } \\
\text { width }\end{array}$ & $\begin{array}{l}\text { 1st testes/ } \\
\text { 1st vitellaria }\end{array}$ & $\begin{array}{l}\text { Testis size } \\
(\mathrm{L} / \mathrm{W}) \\
\mu \mathrm{m}\end{array}$ & $\begin{array}{l}\text { Cirrus-sac } \\
\text { size }(\mathrm{L} / \mathrm{W}) \\
\mu \mathrm{m}\end{array}$ & $\begin{array}{l}\text { Vitelline fol- } \\
\text { licles (L/W) } \\
\mu \mathrm{m}\end{array}$ & & $\begin{array}{l}\text { Arms } \\
(\mathrm{L} / \mathrm{W})\end{array}$ & $\begin{array}{l}\text { Eggs } \\
(\mathrm{L} / \mathrm{W}) \\
\mu \mathrm{m}\end{array}$ \\
\hline $\begin{array}{l}\text { Barbus } \\
\text { altianalis }\end{array}$ & Uga & $4-26$ & $80-2.06$ & $70-2.02$ & $27-\mathbf{1 . 8 0}$ & & $\begin{array}{l}155-229 \\
124-191\end{array}$ & $\begin{array}{l}675-1,050 \\
679-750\end{array}$ & & 1.24 & & $\begin{array}{l}61-76 \\
42-49\end{array}$ \\
\hline $\begin{array}{l}\text { Barbus } \\
\text { barbulus }\end{array}$ & $\operatorname{Iraq}^{2}$ & 15-20 & 1.15-1.89 & $1.34-1.62$ & $92-1.43$ & & & & & $\mathbf{0 . 8 5}-1.54$ & & $\begin{array}{l}55-70 \\
36-41\end{array}$ \\
\hline $\begin{array}{l}\text { Barbus } \\
\text { callensis }\end{array}$ & Morocco $^{3}$ & $21-22$ & $1.39-1.70$ & $1.51-2.15$ & 0.66-1.35 & $\begin{array}{l}4.30-4.80 \\
1.07-1.66\end{array}$ & & & & $1.23-1.35$ & & $\begin{array}{l}\mathbf{5 4}-72 \\
37-50\end{array}$ \\
\hline $\begin{array}{l}\text { Barbus } \\
\text { grypus }\end{array}$ & $\mathrm{Iraq}^{4}$ & $17-38$ & 1.21 & $\mathbf{1 . 2 4}-1.81$ & .44 & & & $\begin{array}{l}562-1,060 \\
635-853\end{array}$ & & 47 & & $\begin{array}{l}57-73 \\
35-44\end{array}$ \\
\hline $\begin{array}{l}\text { Barbus } \\
\text { tropidolepis }\end{array}$ & Tanzania $^{5}$ & 18 & 1.73 & 1.65 & 003 & & & $\begin{array}{l}589 \\
712\end{array}$ & & 1.36 & & $\begin{array}{l}55-66 \\
\mathbf{3 5}-43\end{array}$ \\
\hline $\begin{array}{l}\text { Capoeta c. } \\
\text { sevangi }\end{array}$ & Armenia $^{6}$ & $43-47$ & $2.00-\mathbf{3 . 1 3}$ & $1.25-2.12$ & $1.11-1.54$ & $\begin{array}{l}2.52-3.95 \\
1.64-2.36\end{array}$ & $\begin{array}{l}153-256 \\
135-184\end{array}$ & $\begin{array}{l}\text { 995-1,176 } \\
787-802\end{array}$ & $\begin{array}{c}101-158 \\
83-98\end{array}$ & $1.47-\mathbf{2 . 1 1}$ & $\begin{array}{l}1.31-\mathbf{1 . 9 2} \\
0.49-\mathbf{0 . 8 1}\end{array}$ & $\begin{array}{l}56-76 \\
43-56\end{array}$ \\
\hline $\begin{array}{l}\text { Capoeta } \\
\text { damascina }\end{array}$ & $\operatorname{Iran}^{7}$ & 33 & 1.18 & 1.44 & 0.91 & $\begin{array}{l}2.33 \\
1.51\end{array}$ & & $\begin{array}{l}717 \\
613\end{array}$ & & 0.92 & $\begin{array}{l}1.07-1.16 \\
\mathbf{0 . 2 7}-0.36\end{array}$ & $\begin{array}{l}62-73 \\
36-41\end{array}$ \\
\hline $\begin{array}{l}\text { Luciobarbus } \\
\text { bocagei }\end{array}$ & Portugal $^{8}$ & $16-41$ & $0.6-1.4$ & $0.84-1.28$ & $0.84-1.28$ & $\begin{array}{c}1.56-2.65 \\
2.40\end{array}$ & $\begin{array}{l}70-220 \\
70-180\end{array}$ & $\begin{array}{l}460 \\
540\end{array}$ & $\begin{array}{l}40-120 \\
40-100\end{array}$ & $0.60-1.10$ & $0.70-2.00$ & $\begin{array}{l}46-63^{*} \\
27-41^{*}\end{array}$ \\
\hline $\begin{array}{l}\text { Luciobarbus } \\
\text { bocagei }\end{array}$ & Portugal $^{9}$ & $14-21$ & $0.63-1.44$ & $1.19-\mathbf{2 . 1 5}$ & $0.64-1.22$ & $\begin{array}{l}3.31 \\
1.91\end{array}$ & $\begin{array}{l}157-208 \\
122-174\end{array}$ & $\begin{array}{l}637 \\
467\end{array}$ & $\begin{array}{l}88-165 \\
65-126\end{array}$ & .98 & $\begin{array}{l}0.58-1.63 \\
0.15-0.34\end{array}$ & $\begin{array}{l}61-63 \\
36-40\end{array}$ \\
\hline $\begin{array}{l}\text { Silurus } \\
\text { triostegus }\end{array}$ & $\operatorname{Iraq}^{10}$ & $18-26$ & $1.70-2.33$ & $1.24-1.58$ & $0.93-1.05$ & $\begin{array}{l}2.55-3.13 \\
2.19-\mathbf{2 . 4 6}\end{array}$ & $\begin{array}{l}154-231 \\
113-173\end{array}$ & $\begin{array}{l}652-688 \\
822-823\end{array}$ & $\begin{array}{l}84-186 \\
62-142\end{array}$ & $1.50-1.82$ & $\begin{array}{l}0.78-1.05 \\
0.38-0.44\end{array}$ & $\begin{array}{l}57-69 \\
37-46\end{array}$ \\
\hline
\end{tabular}

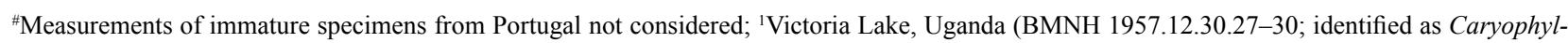
laeus laticeps); ${ }^{2}$ Locality not provided (specimens macerated, with vacuolized, inflated testes and vitelline follicles; IPCAS C-48/4); ${ }^{3}$ Atlas Mountains, Morocco; ${ }^{4}$ Locality not provided (IPCAS C-48/2); ${ }^{5}$ Tanganiyka Lake at Kiranda, Tanzania (BMNH 1928.5.22.85; identified as Caryophyllaeus laticeps); ${ }^{6}$ Sevan Lake - type locality (GELAN 85/Cest); ${ }^{7}$ Zayande River at Esfahan, Iran (A. Sadighian; BMNH 1979.9.27.1-10); ${ }^{8}$ Este River, north of Porto, Portugal (BMNH 1996.6.20.1-17; identified as K. baltica; measurements according to Chubb et al. 1997); ${ }^{9}$ Este River, north of Porto, Portugal (new material; 1 gravid and 1 immature specimens); ${ }^{10}$ Locality not provided (BMNH $\left.1986.3 .10 .59-65\right)$; *Eggs measured by the present authors were 54-65 $\mu \mathrm{m}$ long and 32-37 $\mu \mathrm{m}$ wide.

A-shaped ovary in T. neimongkuensis. However, some specimens of $K$. sinensis have the ovary of the same shape (Fig. 1D). Both species are in fact identical in their morphology and are considered conspecific, similarly as Tsengia xiamenensis Liu, Yang et Lin, 1995, described from common carp in Xiamen, China (Liu et al. 1995).

The original distribution area of $K$. sinensis was limited to eastern Asia (China and Russian Far East), but the tapeworm was imported with grass carp, Ctenopharyngodon idella, and common carp, Cyprinus carpio, to many European countries and North America (USA). The history of introduction of $K$. sinensis to Europe and North America was reviewed by Oros et al. (2009).

Khawia armeniaca (Cholodkovsky, 1915) Shulman, 1958 Fig. 2 Synonyms: Caryophyllaeus armeniacus Cholodkovsky, 1915; Khawia barbi Rahemo et Mohammad, 2002 - new synonym; Khawia lutei Al-Kalak et Rahemo, 2003 - new synonym; Khawia baltica of Chubb et al. (1997).

Material examined: Four spec. from Capoeta capoeta sevangi, Lake Sevan, Armenia, vii. 1976 (GELAN No. 85/Cest), 14 spec. from Barbus bynni (Forsskål), Nile River in Cairo, Egypt, ii.-iii. 1972 (F. Moravec; IPCAS C-48/1); 17 spec. from Varicorhinus damascini [= Capoeta damascina (Valenciennes)], Zayande (Zaindeh) River at Esfahan, Iran (A. Sadighian - see Williams et al. 1980; BMNH 1979.9.27.1-10); two spec. from Silurus triostegus Heckel, Iraq (J.A. Al-Daraji; BMNH 1986.3.10.59-65); three spec. from Barbus callensis Va- lenciennes, Atlas Mountains, Morocco (R.Ph. Dollfus; IPCAS C-48/5); nine spec. identified as K. baltica from Luciobarbus bocagei (Steindachner), Este River, north of Porto, Portugal, vi.-vii. 1989 (A. Saraiva and J.C. Eiras; BMNH 1996.6.20.1-17; see Chubb et al. 1997); four spec. from L. bocagei, Este River, Portugal, ix. 2009 (T. Scholz; IPCAS C-48/6); two spec. identified as Caryophyllaeus laticeps from Barbus altianalis Boulenger, Lake Victoria, Uganda (BMNH 1957.12.30.27-30); one spec. identified as C. laticeps from Barbus tropidolepis Boulenger, Lake Tanganiyka at Kiranda, Tanzania (BMNH 1928.5.22.85). In addition, five spec. identified as Khawia sp. from Barbus barbulus Heckel (IPCAS C-48/4), three spec. from Barbus grypus Heckel (IPCAS C-48/2), all collected by S. Abdullah in Iraq (locality and date not provided), and 11 spec. from B. grypus from the Tigris River in Mosul, Iraq, collected in ix. 2000 by S.N. Al-Kalak (MHNG 32010, 32017 and 32018), were examined.

Diagnosis (measurements of specimens from different hosts and countries in Table 4): Body 15-47 mm long; maximum width $1.15-3.13 \mathrm{~mm}$. Scolex bulbate, slightly wider (width $1.24-2.15 \mathrm{~mm}$ ) than neck (width $0.66-$ $1.80 \mathrm{~mm}$ ), with oval anterior end. Testes numerous, estimated number 150-640 $(\mathrm{n}=8)$, oval to almost spherical, $106-330 \times 76-252$, begin posterior to vitelline follicles, reaching posteriorly up to anterior margin of cirrus-sac. Cirrus-sac widely oval to spherical, thick-walled, 3441,176 × 446-947. Ovary bilobed, butterfly-shaped, i.e., with short and wide lateral arms, follicular, near posterior extremity. Total width of ovary $0.85-2.11 \mathrm{~mm}$; lateral 
arms $0.71-1.92 \mathrm{~mm}$ long and $0.27-0.81 \mathrm{~mm}$ wide. Vagina tubular, nearly straight, proximally joining with uterus to form uterovaginal canal. Seminal receptacle 155-518 $\times$ 88-281. Vitelline follicles cortical, oval, variable in size, $47-280 \times 32-221$, begin $0.99-2.46 \mathrm{~mm}$ from anterior extremity, reach posteriorly to anterior half of cirrus-sac; follicles may be present alongside preovarian uterine loops. Postovarian follicles relatively few, 37-109 $(n=8)$ in number, occupying small area near posterior extremity, few solitary vitelline follicles located around posterior arms of ovary or even do not reach to ovary. Uterus tubular, reaching anteriorly to posterior margin of cirrus-sac. Eggs large, oval, operculate, unembryonated, 54-76 × 35-56 $(\mathrm{n}=34$, intrauterine eggs $)$.

Type host: Sevan khramulya, "Capoëta sp." [= Capoeta capoeta sevangi (De Filippi) - see Popov 1924] (Cyprinidae: Barbinae).

Type locality: Lake Goktscha (= Lake Sevan), Armenia. Type specimens: Not available, not known to exist (materials of N. Cholodkovsky were not deposited in the most important helminthological collections of the former Soviet Union, i.e., GELAN and ZIRAS)

Definitive hosts: Capoeta bushei Kessler, Capoeta capoeta capoeta (Güldenstädt); *Capoeta capoeta sevangi, *Capoeta damascina, Carasobarbus luteus, *Luciobarbus bocagei (all Cyprinidae: Barbinae), *Coregonus lavaretus L. (Salmonidae: Coregoninae), Salmo ischchan Kessler (Salmonidae: Salmoninae) and *Silurus triostegus (Siluridae) (three latter fish species may be atypical hosts).

Life cycle: Poddubnaya and Karen (2003) found Potamothrix alatus paravanicus (= Potamothrix hammoniensis) (Oligochaeta: Tubificidae) to serve as the natural intermediate host of $K$. armeniaca in the type locality (Lake Sevan), with prevalence of $0.5-3 \%$ and intensity $1-7$ larvae. Begoyan (1977), who studied the occurrence and maturation of $K$. armeniaca in the definitive host, Varicorhinus capoeta sevangi (= Capoeta capoeta sevangi), from Lake Sevan in Armenia, estimated prepatent period to take at least 5 months.

Distribution: Asia (Armenia, Azerbaidjan, Georgia, Iran, Iraq, Israel), Africa (Egypt, Morocco, Tanzania new geographical record, Uganda - new geographical record), Europe (Portugal - reported as Khawia baltica by Chubb et al. 1997) (Cholodkovsky 1915, Popov 1924, Dinnik 1933, Mikailov 1975, Williams et al. 1980, Rahemo and Al-Kalak 1983, Protasova et al. 1990, present study).

Remarks. The species was very briefly described (no illustrations were provided) under the name Caryophyllaeus armeniacus by Cholodkovsky (1915) from worms found in "Capoëta" (almost certainly Capoeta capoeta sevangi, which is the only barbel occurring in the lake see Popov 1924). More detailed data on the morphology of $C$. armeniacus, including illustrations, were provided by Popov (1924) and later by Kulakovskaya (1961) and Williams et al. (1980). The species was first transferred to Khawia by Shulman (1958), but this new combination was just listed as a footnote (page 195) and in the list of taxa (page 225). Poddubnaya and Karen (2003), who studied the occurrence of $K$. armeniaca in the type host from the type locality, reported the maximum length of tapeworms as much as $25 \mathrm{~cm}$ and intensity of infection reaching up to 700 specimens.

Unlike other species of Khawia, which possess a relatively uniform scolex typical of respective taxon (see Oros et al. 2010), K. armeniaca exhibits variation in the shape of the scolex, the anterior extent of the testes and vitelline follicles (Fig. 2A-C; figs. $1 \mathrm{~K}$ and $3 \mathrm{~A}$ in Oros et al. 2010), and in the number of vitelline follicles alongside the ovary and the size and anterior extent of postovarian vitelline follicles (Fig. 2D-F). However, these differences were not consistent among specimens from different hosts and geographical regions to indicate the existence of morphologically well-defined populations (morphotypes). In addition, specimens studied were fixed with different methods, including strong flattening, and some were obviously dead and thus decomposed when fixed, which may have caused the differences observed (see, e.g., Pool and Chubb 1985, Oros et al. 2010).

Consequently, the morphological differences listed above are herein considered to represent intraspecific variability of a morphologically variable species that occurs in a wide spectrum of barbels from a large distributional area ranging from southwestern Europe (Portugal) to middle Asia (Iran), with new records from equatorial Africa (Tanzania and Uganda - tapeworms misidentified as Caryophyllaeus laticeps), i.e., from the Ethiopian Region. All tapeworms from barbels, including specimens from the type host and type locality (GELAN 85/Cest) studied by the present authors and by Popov (1924), share the following characteristics considered to be typical of $K$. armeniaca and absent in any other species of Khawia, i.e., a butterfly-shaped, follicular ovary with short and very wide, almost oval lateral arms, a small group of postovarian vitelline follicles (less than 110 in number), with few solitary vitelline follicles located around the posterior arms of the ovary or even not reaching to the ovary, a widely oval to spherical cirrus-sac, and a simple, bulbate scolex with the smooth anterior margin.

Chubb et al. (1997) reported K. baltica from Barbus barbus bocagei (= Luciobarbus bocagei) from northwestern Portugal. Examination of voucher specimens deposited in The Natural History Museum in London (BMNH 1996.6.20.1-17) has shown that $K$. armeniaca was misidentified (Fig. 2F). However, analysis of sequences of newly collected specimens from Portugal has shown some nucleotide differences between samples of $K$. armeniaca from the type locality (Armenia) and presumably conspecific worms from Portugal (Fig. 9). It cannot be ruled out that tapeworms from Portugal represents in fact a sibling species of $K$. armeniaca, but new, properly fixed materials of Khawia tapeworms from different hosts and 

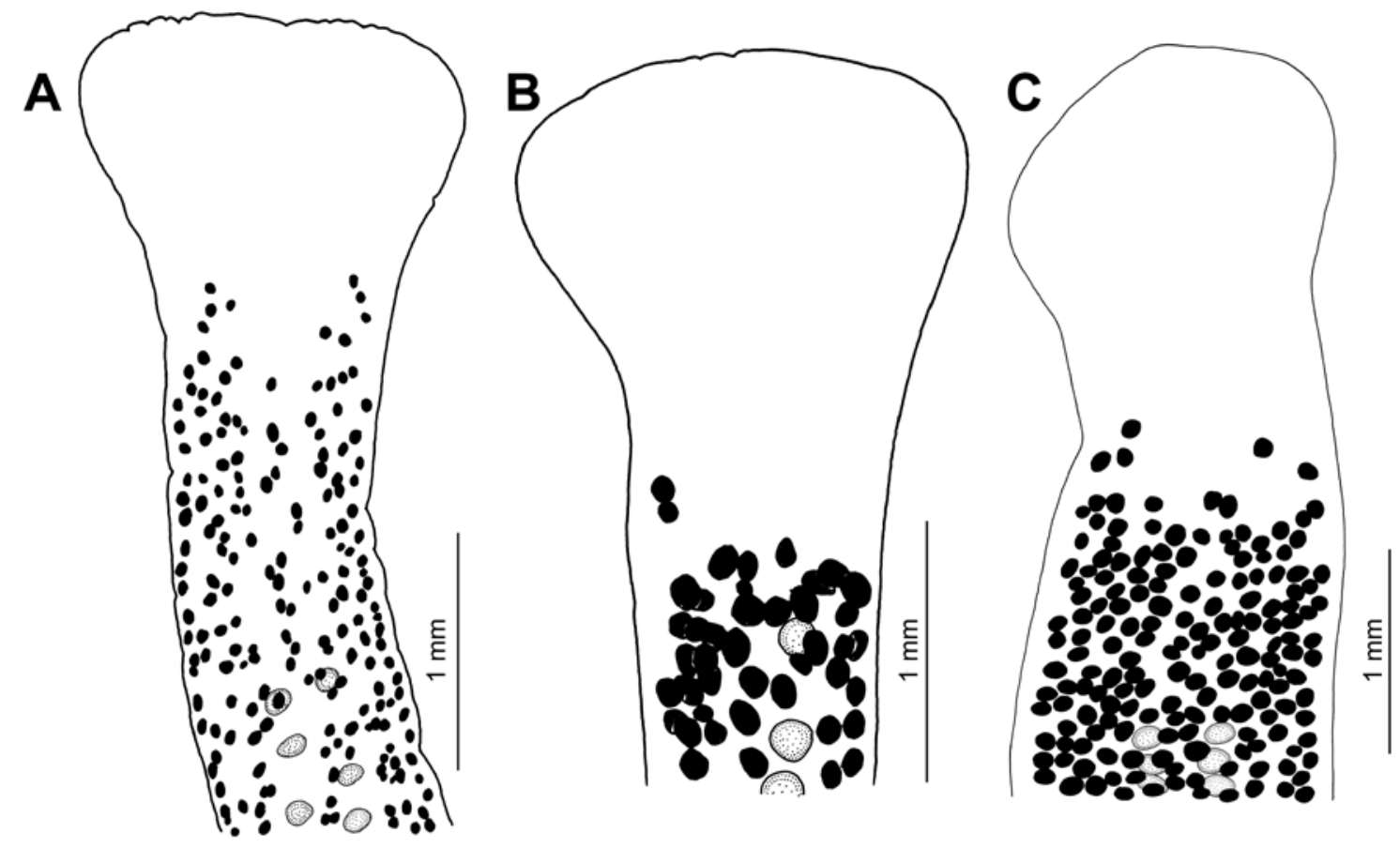

D

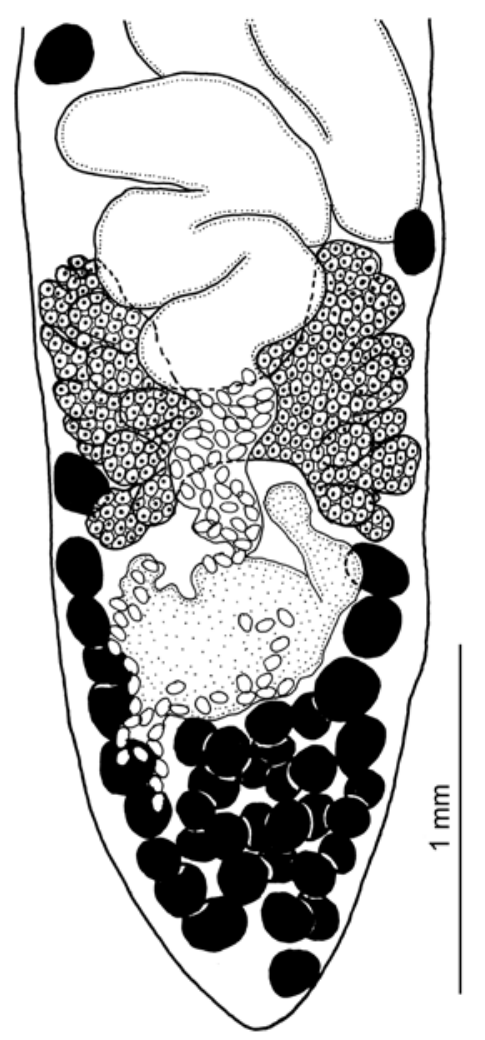

E

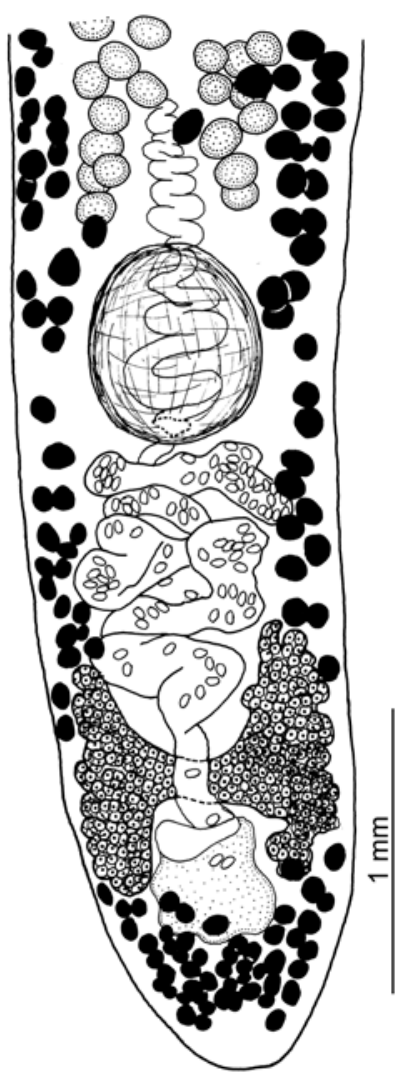

$\mathbf{F}$

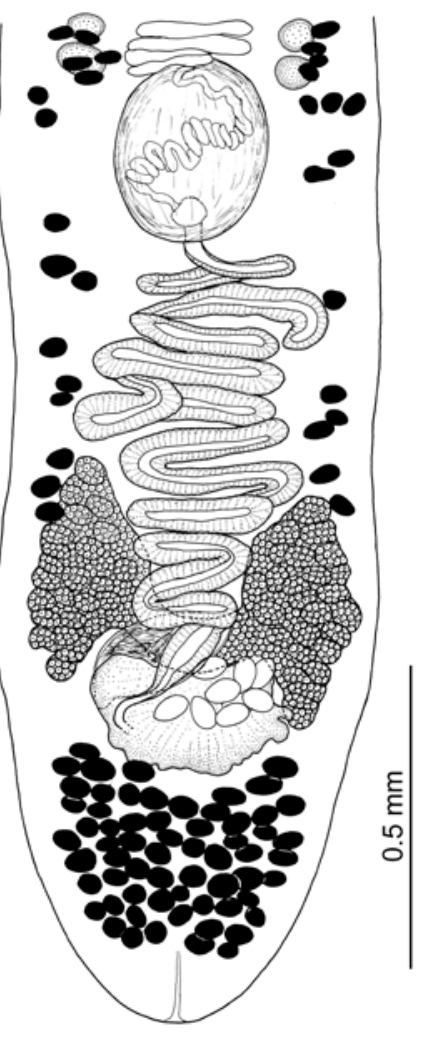

Fig. 2. Khawia armeniaca (Cholodkovsky, 1915) from Barbus grypus, Iraq (A, B, E) (MHNG 32010, 32017, 32018), B. altianalis, Uganda (C) (BMNH 1957.12.30.27-30), B. barbulus, Iraq (D) (IPCAS C-48/4) and B. bocagei, Portugal (F) (BMNH 1998.6.20.114; identified as $K$. baltica). A-C - anterior part of the body (note variation in the anterior position of the first vitelline follicles and testes); D-F - posterior part of the body, dorsal (note butterfly-shaped, follicular ovary and relatively few postovarian vitelline follicles of different size). 
regions, especially from northern and eastern Africa, are necessary to discover possible cryptic species within the $K$. armeniaca species complex.

Two other species of Khawia were described from the same host, Barbus luteus Heckel [= Carasobarbus luteus (Heckel)], and locality, Tigris River in Mosul, Iraq (Rahemo and Mohammad 2002, Al-Kalak and Rahemo 2003). Khawia barbi Rahemo et Mohammad, 2002 was described very briefly and almost no measurements were provided. The species was distinguished from K. armeni$a c a$, which was also reported from barbels in Iraq by the same authors (Rahemo and Al-Kalak 1993), by only two doubtful characters: (i) $K$. barbi was reported to possess a constriction in the region of the cirrus-sac (absent in $K$. armeniaca) and (ii) its scolex was described not to be frilled unlike that of $K$. armeniaca, the scolex of which should be frilled (Rahemo and Mohammad 2002).

However, the alleged constriction of $K$. barbi in the preovarian region is apparently an artifact as a result of damage of the worms (see fig. 2 in Rahemo and Moham$\operatorname{mad} 2002$ ) and the scolex of $K$. armeniaca is not frilled as claimed by Rahemo and Mohammad (2002), but it has in fact a smooth, entire anterior margin (Fig. 2A-C), similarly as that of $K$. barbi. Reliability of the above-mentioned diagnostic characteristics of $K$. barbi could not be verified, because type specimens were not available despite several requests to one of the authors (Z.I.F. Rahemo).

Description of Khawia lutei Al-Kalak et Rahemo, 2003 was also incomplete and inadequate, because most taxonomically important characteristics were not described and almost no measurements were provided. In addition, the following morphological data were doubtful: (i) internal seminal vesicle is in fact a convoluted internal sperm duct within the cirrus-sac, which is typical of all species of Khawia; (ii) vitelline follicles were reported to be "in cortex and medulla", which has never been observed in any species of the genus [only postovarian vitelline follicles may be both in the medulla and cortex in some species, such as $K$. japonensis and $K$. sinensis - Yamaguti (1934), Hsü (1935)]; (iii) histological sections, documented by seven photomicrographs of very low quality, were based on specimens with disintegrated internal tissues, which is most obvious from figs. 5, 6 and 11 in Al-Kalak and Rahemo (2003); (iv) full formation of an oncospehere in the uterus is doubtful, because the oncosphere was formed in the egg shell released to water in all three species of Khawia studied experimentally (Kulakovskaya 1961, 1963, Demshin 1978, 1984, Demshin and Dvoryadkin 1980, Scholz 1991b, 1993).

The differential diagnosis of $K$. lutei from congeneric taxa was also insufficient and misleading, and $K$. armeni$a c a$ was distinguished by unspecified differences in the size of the cirrus-sac, separate genital openings and lack of a seminal vesicle (Al-Kalak and Rahemo 2003). In fact, $K$. lutei, similarly as $K$. barbi discussed above, is morphologically indistinguishable from $K$. armeniaca, which occurs in the same fish host and has also been reported from the same geographical region (Williams et al. 1980, Rahemo and Al-Kalak 1993). All three taxa share characteristics typical of $K$. armeniaca, especially a butterflyshaped, follicular ovary, and a small group of postovarian vitelline follicles, which are features unique among all species of Khawia.

On the basis of morphological similarity in all characteristics considered to be of diagnostic value, both species of Khawia from Iraq are synonymized with $K$. armeni$a c a$. This new synonymy, well supported by morphological data, the identical host spectrum and geographical distribution, could not be confirmed by molecular data, because ethanol-fixed specimens of $K$. barbi and K. lutei were not available.

Specimens from Barbus altianalis and B. tropidolepis from Uganda and Tanzania, respectively (Fig. 2C; Table 4), all designated as Caryophyllaeus laticeps, were misidentified and they actually belong to $K$. armeniaca . However, new material of tapeworms from African barbels should be obtained for a detailed study of morphological and genetic variability of this cestode, the host spectrum of which is much wider than that of the other species of Khawia. The geographical distribution of $K$. armeniaca is large and includes two principal zoogeographical regions, i.e., the Palaearctic and Ethiopian Regions, thus representing the only Khawia species that occurs beyond the Holarctic Region. Further morphological and genetic studies are needed to clarify taxonomic status of $K$. armeniaca populations from different fish hosts and geographical regions.

Khawia baltica Szidat, 1941

Figs. 3, 8A

Material examined: 47 spec. from the Czech Republic: North Bohemia - Břehyně, 1976-1982 (F. Moravec); South Bohemia - fishponds around Jindřichův Hradec, Nové Hrady and Třeboň, 1985-1990 (T. Scholz); iv. and xii. 2010 (R. Kuchta, C. Levron and M. Oros) (IPCAS C-42/1); two spec. from Switzerland (precise locality unknown, most probably canton Neuchâtel, 1933 and 1934; MHNG - not registered), all specimens from Tinca tinca (L.).

Diagnosis (based on 10 specimens from the Czech Republic): Body length 23-55 mm, maximum width 0.9$2.6 \mathrm{~mm}$. Scolex flabellate, $1.9-3.9 \mathrm{~mm}$ wide, markedly wider than neck, with wrinkles along front edge. Neck $0.48-1.76 \mathrm{~mm}$ wide. Testes numerous, estimated number 550-750 ( $\mathrm{n}=2)$, oval, 70-320 × 50-260, medullary, begin at very long distance, $6.9-11.8 \mathrm{~mm}$, from anterior extremity, 3.8-7.7 $\mathrm{mm}$ posterior to first vitelline follicles. Posteriorly, testes reach to anterior margin of cirrus-sac, rarely to its posterior half. Cirrus-sac thin-walled, difficult to observe, oval, $0.61-0.85 \times 0.39-0.53 \mathrm{~mm}$. Ovary bilobed, H-shaped, 1.1-1.9 mm wide, with long and slender ovarian arms, up to $3.3-3.8 \mathrm{~mm}$ long and $0.26-0.31$ $\mathrm{mm}$ wide. Vagina tubular, slightly sinuous, forming elon- 


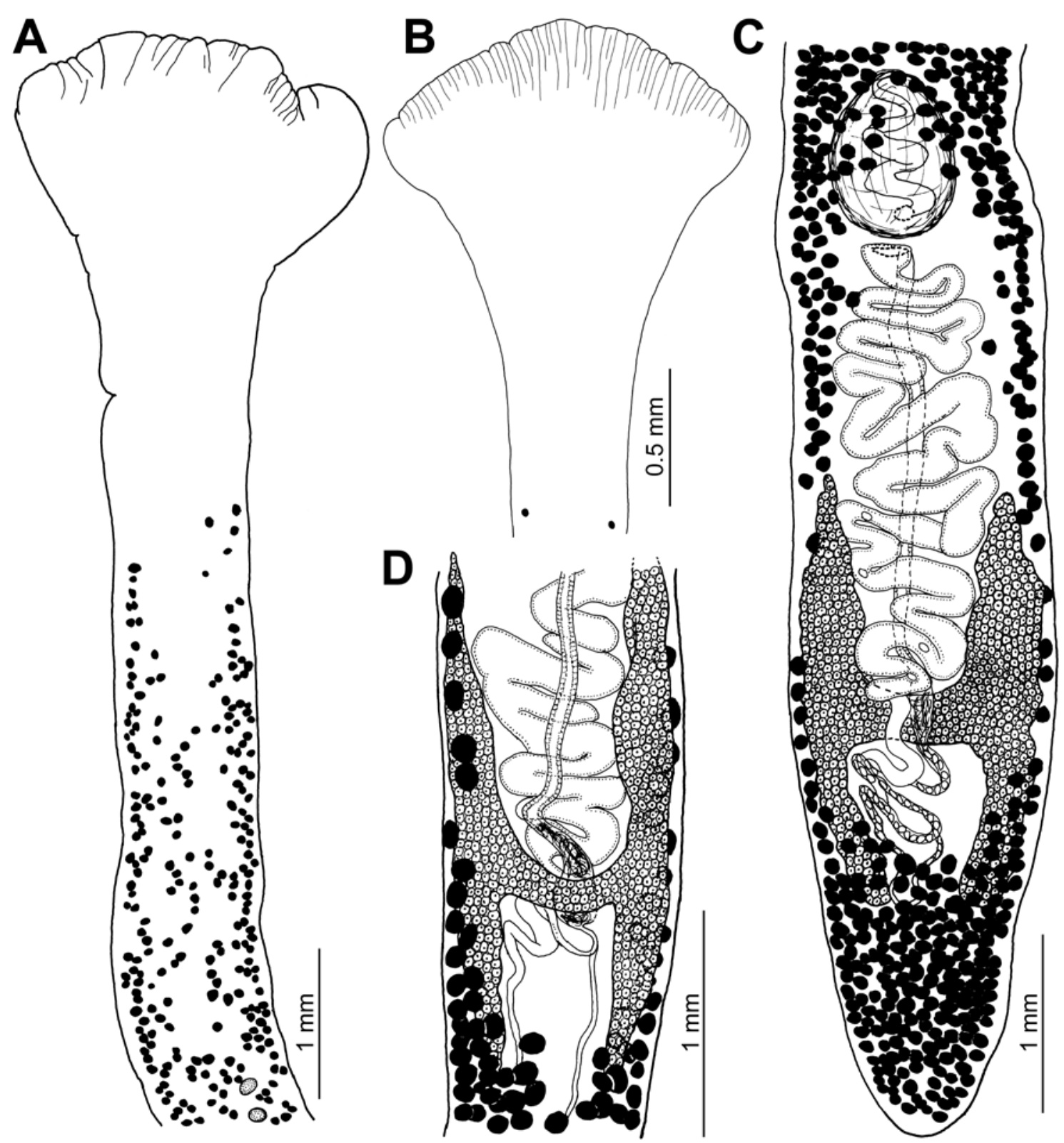

Fig. 3. Khawia baltica Szidat, 1941 from Tinca tinca, Czech Republic (IPCAS C-42). A, B - anterior part of the body (note the presence of grooves on the anterior margin of the scolex and position of the first vitelline follicles and testes - in A, the latter situated very far posterior to vitelline follicles); $\mathbf{C}$ - posterior part of the body, dorsal (note the presence of numerous vitelline follicles alongside the preovarian uterine loops); D - ovarian region, ventral (note variation in the number of vitelline follicles alongside the ovarian arms).

gate seminal receptacle in its proximal part, $135-276 \times$ 68-106. Vitelline follicles cortical, usually spherical, $40-270 \times 20-190$ in size. First vitelline follicles begin $3.0-4.9 \mathrm{~mm}$ posterior to anterior extremity, reaching posteriorly alongside cirrus-sac to uterine loops; a few follicles present alongside ovary. Postovarian follicles extensive. Uterus tubular, with numerous loops reaching anteriorly to level of posterior margin of cirrus-sac. Eggs oval, operculate, unembryonated, 59-73 × 39-46 ( $\mathrm{n}=30$, intrauterine eggs).

Type host: Tench, Tinca tinca (L.) (Cyprinidae: Cyprininae).
Type locality: Rossitten, Courland Spit (Kuhrische Nehrung), East Prussia (now the Russian enclave of Kaliningrad).

Type specimens: Do not exist (see Calentine and Ulmer $1961-$ p. 800).

Definitive host: *Tinca tinca; other hosts are considered to be doubtful (see Remarks).

Life cycle: Eggs are laid unembryonated and the infective oncosphere is formed after two weeks at $20-22^{\circ} \mathrm{C}$ (Scholz 1993). The oligochaete Tubifex tubifex was suitable experimental intermediate host and metacestodes 
(plerocercoids) were formed after one month of development at $20-22^{\circ} \mathrm{C}$. Growth in experimentally infected definitive host, tench, kept at $15-16^{\circ} \mathrm{C}$, was slow and juvenile tapeworms resembling plerocercoids from tubificids were found as late as 11 weeks post infection (Scholz 1993).

Distribution: Central Europe (Czech Republic, Poland, Switzerland - new geographical record), European part of the former USSR (Lithuania, Russia - Kaliningrad District, Ukraine), Asia (Georgia) (Szidat 1941, Janiszewska 1954, Kulakovskaya 1961, Moravec 1984, Protasova et al. 1990).

Remarks. Szidat (1941) described the morphology of $K$. baltica in detail, but provided only very few measurements. Since the original description, the validity of $K$. baltica has never been questioned because the tapeworm differs in its morphology from congeneric species. The most typical characteristics are a flabellate scolex with shallow grooves on its anterior margin, the presence of vitelline follicles lateral to preovarian uterine loops, with some follicles present also alongside the ovarian arms, and the first testes situated well posterior to the first vitelline follicles.

Dubinina (1987) and Protasova et al. (1990) reported other cyprinids as definitive hosts of $K$. baltica, namely barbel Barbus barbus (L.), rudd Scardinius erythrophthalmus (L.), bleak Alburnus alburnus (L.) and bream Abramis brama (L.). However, these host records are considered to be doubtful and need verification since no voucher specimens of tapeworms from these fish are deposited in the principal helminthological collections of Russia (GELAN and ZIRAS).

Chubb et al. (1987) reported K. baltica from the barbel Luciobarbus bocagei from several rivers in northwestern Portugal. However, the examination of vouchers and newly collected specimens has shown that $K$. armeniaca was most probably misidentified (see above). Therefore, $K$. baltica is considered to be a specific parasite of tench until reliable records from other fish confirm its wider spectrum of definitive hosts.

Khawia japonensis (Yamaguti, 1934) Hsü, 1935 Fig. 4 Synonyms: Caryophyllaeus japonensis Yamaguti, 1934; Bothrioscolex japonensis (Yamaguti, 1934) Szidat, 1937; Khawia iowensis Calentine et Ulmer, 1961 - new synonym; Khawia cyprini Li, 1964 - new synonym.

Material examined: Holotype and paratype of Caryophyllaeus japonensis from Lake Biwa, Shiga Prefecture, Japan (MPM, Coll. No. SY3011); three spec. identified as Khawia sinensis from Lake Ilchya, Far East, Russia, viii. 1959 and 1960 (GELAN - no collection number); one spec. from Lake Suwa, Nagano Prefecture, Japan, v. 1975 (T. Shimazu; IPCAS C-348); three spec. from Lake Biwa, v. 2001 (T. Scholz; IPCAS C-348); three spec. from Aqua Restoration Research Centre, Gifu, Gifu Pref.,
Japan, vi. 2001 and iv. 2007 (M. Urabe, T. Scholz and R. Kuchta); one spec. from Vladivostok, Russia, 2007 (M. Shedko; IPCAS C-348); five spec. from Masi Torello, Italy, viii.-ix. 2010 (B.S. Dezfuli - see Scholz et al. 2011), 29 spec. from Ben En, Nhu Thanh Province, and Red River delta, Ha Dong Province, Vietnam, ix.-x. 2010 (T. Scholz; IPCAS C-348), all specimens from Cyprinus carpio. In addition, two paratypes of $K$. iowensis (=K. japonensis) from the Iowa River, USA, 1960 (M.J. Ulmer and R.L. Calentine; USNPC 39068) and six spec. from USA, North America (provided by J.S. Mackiewicz), all from $C$. carpio, were examined. Type specimens of $K$. cyprini ( $=K$. japonensis), reported to have been deposited in the Institute of Zoology, Academia Sinica, Peking (Beijing), China, were not available and it is uncertain whether they actually exist.

Diagnosis (based on six specimens from Japan collected in 2001 and 2007): Body 19.5-24.5 mm long; maximum width $1.2 \mathrm{~mm}$. Scolex cuneifimbriate, slightly widened, $1.3-1.5 \mathrm{~mm}$ wide, with fimbriae or small lobes on front edge. Neck $0.9-1.1 \mathrm{~mm}$ wide. Testes numerous, estimated number 180-250 ( $\mathrm{n}=3)$, spherical, large, 160-250 × 128-191, begin 1.2-1.5 mm from anterior extremity, usually anterior to anteriormost vitelline follicles, reaching posteriorly to cirrus-sac and surrounding its anterior third. Cirrus-sac oval, thick-walled, 0.84-0.86 $\times 0.59-0.60 \mathrm{~mm}$. Ovary bilobed, H-shaped, total width up to $0.8 \mathrm{~mm}$; lateral arms 1.9-2.2 $\mathrm{mm}$ long and 0.19$0.25 \mathrm{~mm}$ wide. Vagina tubular, nearly straight, proximally joining with uterus to form uterovaginal canal that opens into genital atrium. Seminal receptacle dorsal to ovarian isthmus, 251-537 × 119-274. Vitelline follicles oval, 98$156 \times 87-110$, begin at approximately same level as, or slightly posterior to, first testes, $1.2-1.5 \mathrm{~mm}$ from anterior extremity; posteriorly, follicles present alongside preovarian uterine loops and a few follicles lateral to ovarian lobes. Postovarian follicles extensive, with several follicles surrounding posterior part of ovarian arms. Uterus tubular, sinuous. Eggs oval, operculate, unembryonated, $46-52 \times 32-39(n=30$, intrauterine eggs $)$.

Ty pe host: Common carp, Cyprinus carpio L. (Cyprinidae: Cyprininae).

Type locality: Lake Biwa, Japan.

Type specimens: Meguro Parasitological Museum, Tokyo, Japan (holotype and paratype on the same slide SY3011).

Defin it ive host: *Cyprinus carpio; other fish reported to harbour $K$. iowensis ( $=K$. japonensis) are considered to be atypical hosts (see Remarks).

Life cycle: The tubificid Limnodrilus udekemianus (Oligochaeta) served as suitable intermediate host under experimental conditions (Demshin 1978). Calentine and Ulmer (1961) found fully developed (infective) oncospheres in the eggs of $K$. iowensis (=K. japonensis) after 15 days of development at room temperature. 


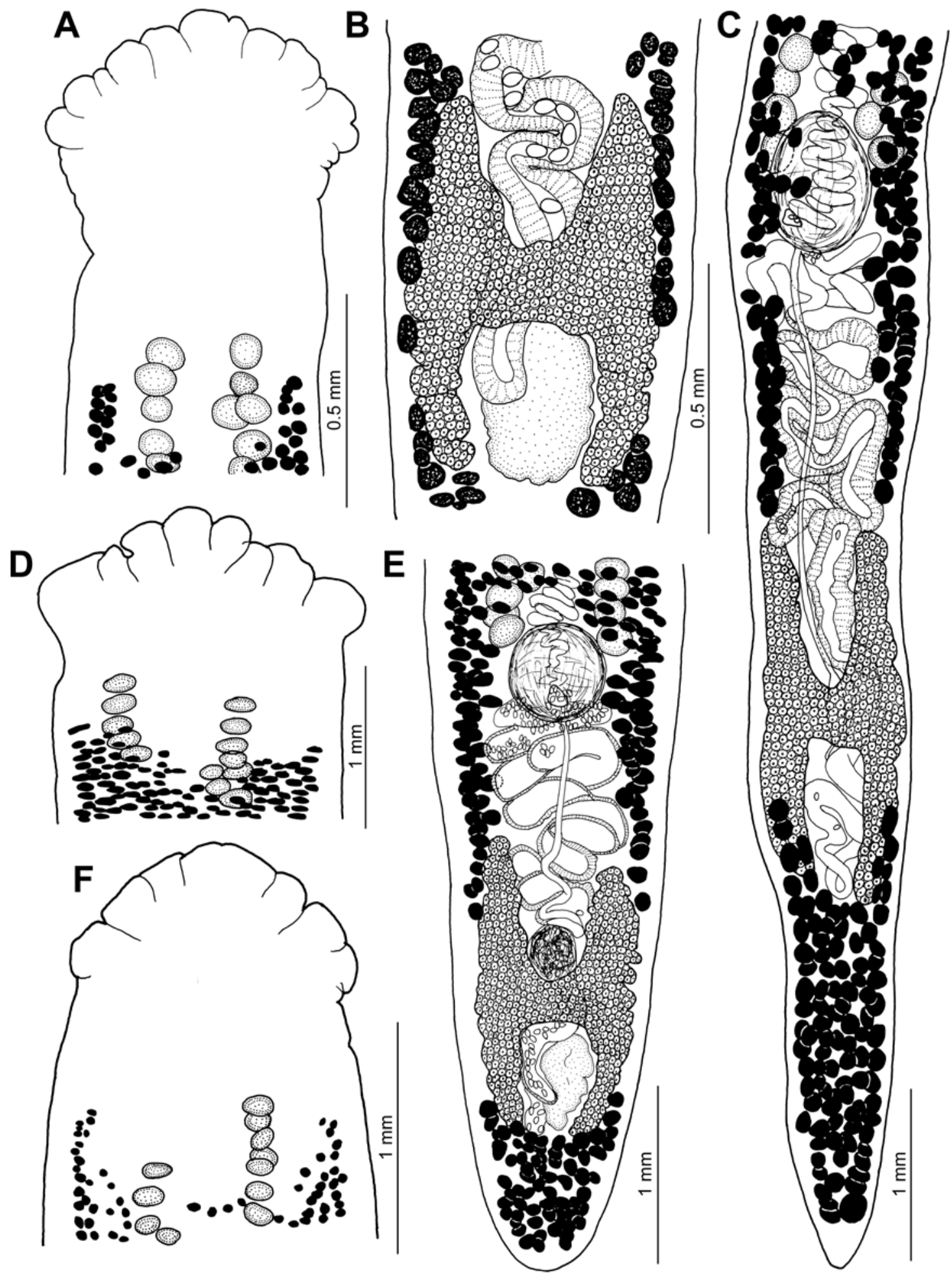

Fig. 4. Khawia japonensis (Yamaguti, 1934) from Cyprinus carpio, Japan (A-C) (IPCAS C-348/1), Far East of Russia (D) (GELAN) and USA (E, F) (IPCAS C-528; originally K. iowensis). A, D, F - anterior part of the body (note fimbriate anterior margin of the scolex and the position of the first testes anterior to the first vitelline follicles); $\mathbf{B}$ - ovarian region, ventral (note presence of numerous vitelline follicles alongside the lateral ovarian arms); $\mathbf{C}, \mathbf{E}$ - posterior part of the body, ventral (note almost complete absence of vitelline follicles alongside lateral ovarian arms). 
Distribution: Asia (Japan, China - Inner Mongolia, Russia - Amur River basin, Vietnam - new geographical record), Europe (Italy - introduced), North America (USA - as K. iowensis) (Yamaguti 1934, Calentine and Ulmer 1961, Kulakovskaya 1961, Li 1964, Dubinina 1971, Protasova et al. 1990, Scholz et al. 2011; present study).

Remarks. The species was briefly described as Caryophyllaeus japonensis from common carp from Lake Biwa in Japan and very few measurements were provided by Yamaguti (1934). Hsü (1935) placed C. japonensis in the newly erected genus Khawia Hsü, 1935 because of the cortical position of vitelline follicles. Szidat (1937), who was not aware of Hsü's paper from 1935, transferred the species to Bothrioscolex Szidat, 1937 as Bothrioscolex japonensis (Yamaguti, 1934), but Markevich (1951) and Fotedar (1958) synonymized Bothrioscolex with Khawia.

Dubinina (1987), who referred to unpublished data by O.P. Kulakovskaya (1969 - abstract of a D.Sc. dissertation), reported $K$. japonensis from a fishery cooperative Lisnevichi in Ukraine, but Protasova et al. (1990) did not mention this finding. However, the occurrence of $K$. japonensis in Europe is possible as a result of import of carp from East Asia, which is indicated by a recent finding of the tapeworm in common carp in northern Italy (Scholz et al. 2011).

Khawia iowensis Calentine et Ulmer, 1961 was described from common carp (a fish imported to North America from Asia) from the Iowa River, Iowa in the USA and then also found in Illinois, North Dakota and Wisconsin (Hoffman 1999). Besides common carp, it has been reported also from non-cyprinids, such as bigmouth buffalo, Ictiobus cyprinellus (Valenciennes), white sucker, Catostomus commersoni (Lacépède) (Catostomidae), and black bullhead, Ameiurus melas (Rafinesque) (Ictaluridae) (Hoffman 1999), but these fish are probably atypical or incidental hosts.

In fact, $K$. iowensis is morphologically indistinguishable from $K$.japonensis because both species have a similar shape of the body, with almost the same width throughout the body, a cuneifimbriate scolex slightly wider than the neck region, the first testes beginning very close posterior to the scolex, usually anterior to the first vitelline follicles, and vitelline follicles forming a continuous band alongside the preovarian uterine loops, with a few isolated follicles alongside the ovarian arms (compare Fig. 4A, B, D, F with Fig. 4C, E).

A close similarity of both the taxa was even admitted by Calentine and Ulmer (1961), who distinguished their new species only by the number of testes in cross sections: in two distinct, dorsal and ventral layers with about seven testes per layer in $K$. japonensis, whereas usually in a single layer of two to six testes in $K$. iowensis (Calentine and Ulmer 1961). However, taxonomic suitability of this character is doubtful because the number of testes may vary throughout the body of caryophyllideans and among different specimens, depending on their state of maturation and body size. Therefore, both species are considered to be identical and $K$. iowensis thus becomes a junior synonym of $K$. japonensis.

Khawia cyprini Li, 1964 was described very briefly, based on specimens from common carp from Lake Wulasuhai in Inner Mongolia, China. Li (1964) differentiated his new species from $K$. japonensis by four doubtful characteristics (table 3 in Li 1964), namely "not enlarged" scolex, which is, however, wider than the neck region, i.e., enlarged, the number of vitelline follicles in cross sections (actually not corresponding to that illustrated in fig. 14 of Li 1964), fulfillment of the parenchyma behind the ovary by vitelline follicles (i.e., the presence of postovarian follicles, which is a feature typical of all Khawia species), and opening of the cirrus into the uterovaginal aperture (documented very schematically in fig. 4 of Li 1964). However, all these characteristics are questionable as to their suitability in differentiating species, because they are subjected to individual, intraspecific variation (number of vitelline follicles) or were not adequately documented in the original description (position of the male genital pore). In fact, $K$. cyprini is identical in its morphology with $K$. japonensis, including the characteristics considered to be species-specific (shape of the scolex, the anterior extent of testes and vitelline follicles, and distribution of vitelline follicles alongside the uterus and ovary), and is newly synonymized with $K$. japonensis.

Khawia parva (Zmeev, 1936) Kulakovskaya, 1961

Figs. 5, 8B

Synonym: Caryophyllaeus parvus Zmeev, 1936.

Material examined: One spec. (syntype) from Carassius carassius (most probably Carassius auratus - see below), Amur River, Far East, Russia, 1936 (G.Ya. Zmeev; ZIRAS 1461); five spec. from Carassius auratus (L.), Lake Bolon, Far East, Russia, probably 1958 (S.S. Shulman; ZIRAS 1462, 1463 and 1466); five spec. from C. auratus, Tom River estuary and Lake Dzhivoskit, Far East, Russia, 1957-1959 (GELAN - no collection number; fish samples Nos. 53/219 and 399); two spec. from Cyprinus carpio from Far East, Russia, locality and sampling date not provided (GELAN - no collection number; fish sample No. 405/650).

Diagnosis (based on Oros and Hanzelová 2007; $\mathrm{n}=13$ ): Body length 28.5-61.0 mm; maximum width 1.5-2.5 mm. Scolex cuneiform, laterally extended, with round, smooth anterior margin. Neck 1.3-2.1 mm wide. Testes numerous, medullary, 195-292 $\times 141-250$, begin $2.7-4.1 \mathrm{~mm}$ from anterior extremity, $0.8-1.6 \mathrm{~mm}$ posterior to first vitelline follicles, rarely anterior to vitelline follicles. Posteriorly, testes reach to anterior margin of cirrussac. Cirrus-sac thin-walled, oval, 0.7-1.0 $\times 0.5-0.7 \mathrm{~mm}$. Ovary bilobed, H-shaped, 1.3-1.9 mm wide; ovarian arms 1.7-3.4 mm long and 227-318 wide, slightly bent inwards posteriorly. Vagina tubular, slightly sinuous. Seminal re- 

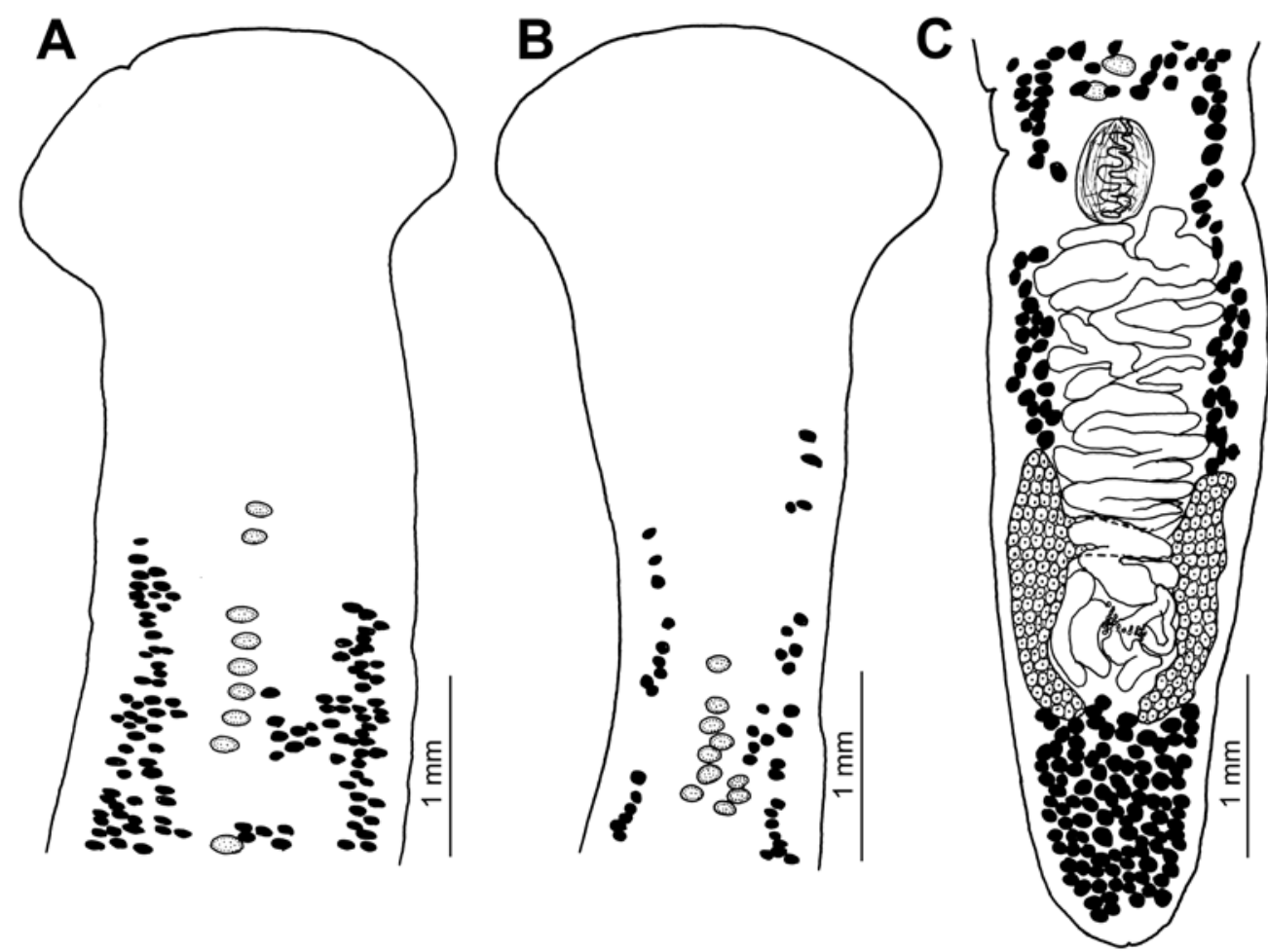

Fig. 5. Khawia parva (Zmeev, 1936) from Carassius auratus, Far East, Russia (GELAN - collection numbers not given). A, B - anterior part of the body; $\mathbf{C}$ - posterior part of the body, dorsal (note vitelline follicles alongside the preovarian uterine loops, but completely absent alongside the ovary; uterine glands lining preovarian loops of the uterus not illustrated).

ceptacle dorsal to ovarian isthmus. Vitelline follicles cortical, 114-160 × 63-102; follicles begin 2.0-3.4 mm posterior to anterior extremity and reach to posterior margin of cirrus-sac; a few follicles present alongside preovarian uterine loops and may reach to level of anterior margin of ovary; follicles absent alongside ovarian arms (absent alongside uterus and ovary in syntype). Postovarian follicles extensive. Uterus tubular, forming numerous loops. Eggs oval, operculate, unembryonated, 43-47 × 28-32 $(\mathrm{n}=30$, intrauterine eggs).

Type host: Crucian carp, "Carassius carassius" (L.) (Cyprinidae: Cyprininae) (probably Carassius gibelio).

Type locality: Amur River (Birobidjan District), Far East, Russia.

Type specimens: ZIRAS (Coll. No. 1461).

Definitive hosts: *Carassius gibelio, C. carassius.

Life cycle: The oncosphere is fully formed after 7 weeks of development in the water and the tubificid oligochaetes Limnodrilus udekemianus and Limnodrilus sp. serve as experimental intermediate hosts; infective plerocercoids were observed after 57-60 days of development (Demshin 1984).

Distribution: Amur River basin, Far East, Russia (Zmeev 1936, Kulakovskaya 1961, Protasova et al. 1990); records from Japan are doubtful (see Remarks).

Remarks. The species was briefly described as Caryophyllaeus parvus by Zmeev (1936) on the basis of two small, most certainly immature specimens from crucian carp (in fact, gold fish was most probably the host of the tapeworms because crucian carp does not occur in this region) from the Amur River in the Russian Far East. Zmeev (1936) did not mention the position of vitelline follicles in relation to the inner longitudinal musculature nor provided drawings of cross sections. Kulakovskaya (1961), who studied tapeworms from crucian carp from the Amur River, transferred the species to Khawia, but misspelled it as "Khavia parvus". This new combination, emended as Khawia parva, has been accepted by most authors, e.g., Dubinina (1971, 1987), Protasova et al. (1990), Scholz et al. (2001). In contrast, Calentine and Ulmer (1961) and Schmidt (1986), who did not study specimens of $K$. par$v a$, kept the species in Caryophyllaeus and Mackiewicz (1972) listed K. parva among species incertae sedis. Recently, Oros and Hanzelová (2007) redescribed the species and differentiated it from another species parasitic in crucian carp and goldfish, $K$. rossittensis.

Tapeworms apparently conspecific with $K$. parva, reported to have been found in common carp (C. carpio), are deposited in the helminthological collection of the former GELAN in Moscow. However, this finding has never been reported by Russian authors (Dubinina 1987, Protasova et al. 1990) and needs confirmation. Scholz et al. (2001) misidentified strongly flattened specimens of $K$. rossittensis from Japan as $K$. parva and thus it seems that the latter species does not occur in Japan. 
Khawia rossittensis (Szidat, 1937) Markevich, 1951

Fig. 6

Synonyms: Bothrioscolex rossittensis Szidat, 1937; Bothrioscolex dubius Szidat, 1937 - new synonym.

Material examined: Two spec. from Carassius carassius, Russia, v. 1953 (E.G. Sidorov; ZIRAS 1421 and 1422); two spec. from C. carassius, Tisa River, Ukraine, vii. 1962 and 1963 (R. Ergens - see Ergens et al. 1975; IPCAS C-214/1); two spec. from C. carassius, Tisa River, eastern Slovakia, vii. 1964 (R. Žitňan; ESMK1854/64 [3362]); one spec. from C. carassius, Belorussia, date not given (O.P. Kulakovskaya; ZIRAS 1420); two spec. from C. carassius, Bothnian Bay, Finland, vii. 1981 (E.T. Valtonen - see Gibson and Valtonen 1983; BMNH 1983.9.6.1-2), all from Carassius carassius; eight spec. from Carassius auratus auratus (L.) from the Tisa and Latorica rivers, eastern Slovakia, 2002-2003, 2005-2007 (M. Oros and V. Hanzelová; ESMK 43/02, 8/03, 47/03, 52/03, 81/05, 95/05, 554/05, 271/05, 205/06 and 207/07); one spec. from $C$. auratus langsdorfii Valenciennes in Cuvier et Valenciennes, Lake Kizaki, Oomachi, Japan, vi. 1983, two spec. from Carassius sp. from Lake Toro, Shibecha, Hokkaido, Japan, x. 1981 (BMNH 2001.5.30.1), and from Lake Saruruto, Shibecha, Hokkaido, vii. 1984 (all collected by T. Shimazu and misidentified as $K$. parva - see Scholz et al. 2001; BMNH 2001.30.5.1-2, IPCAS C-339/1 and MPM 19796-19797); two juvenile spec. from C. auratus langsdorfii, Lake Biwa, Japan, iv. 2007 (T. Scholz and R. Kuchta); ten spec. from C. auratus grandoculis Temminck et Schlegel, Lake Biwa, Japan, iv. 2007 (M. Urabe; IPCAS C-339/2).

Diagnosis (based on Oros and Hanzelová 2007; $\mathrm{n}=10$ ): Body length 13-27 mm; maximum width 0.6$2.1 \mathrm{~mm}$. Scolex of triangular shape or cuneiform, 0.7$1.7 \mathrm{~mm}$ wide. Neck $0.8-1.7 \mathrm{~mm}$ wide. Testes numerous, estimated number 160 (countable in only one specimen), oval, $108-281 \times 105-230$, begin at short distance, $1.7-$ $2.0 \mathrm{~mm}$ from anterior extremity, $0.1-0.7 \mathrm{~mm}$ posterior to first vitelline follicles. Posteriorly, testes reach to anterior margin of cirrus-sac. Cirrus-sac oval, 0.26-0.57 $\times 0.31$ $0.75 \mathrm{~mm}$. Ovary bilobed, with posterior arms bent inwards, sometimes with arms united, thus becoming inverted A-shaped, 0.5-1.4 mm wide; ovarian arms 1.4-3.1 mm long and 175-275 wide. Vagina tubular, slightly sinuous. Seminal receptacle dorsal to ovarian isthmus, 208-359 $\times$ 142-197. Vitelline follicles cortical, oval, 60-134 × 40 118. First vitelline follicles begin $0.8-2.0 \mathrm{~mm}$ posterior to anterior extremity, reaching to cirrus-sac, with a few follicles alongside preovarian uterine loops, absent alongside ovary. Postovarian follicles extensive. Uterus with numerous loops. Eggs oval, operculate, unembryonated, $44-50 \times 27-31(n=30$, intrauterine eggs $)$.

Ty p e host: Crucian carp, Carassius carassius (L.) (Cyprinidae).
Type locality: Fishpond "Lunk", Rossitten, Courland Spit (Kuhrische Nehrung), East Prussia (now the Russian enclave of Kaliningrad).

Type specimens: Do not exist (see Calentine and Ulmer $1961-$ p. 800).

Definitive hosts: *Carassius auratus (L.), ${ }^{*}$ C. carassius.

Life cycle: Not known.

Distribution: Europe (Belorussia, Finland, Romania, Russia, Slovakia, Ukraine) and Asia (Japan - new geographical record, Kazakhstan, Russia - Siberia) (Szidat 1937, Kulakovskaya 1961, Ergens et al. 1975, Gibson and Valtonen 1983, Oros and Hanzelová 2007, present paper).

Remarks. The species was described incompletely (almost no measurements were provided) by Szidat (1937) as Bothrioscolex rossittensis to accommodate caryophyllidean tapeworms found in crucian carp in East Prussia (now the Kaliningrad enclave of Russia). Markevich (1951) invalidated Bothrioscolex Szidat, 1937 and Fotedar (1958) transferred its species, including B. rossittensis, to Khawia.

Oros and Hanzelová (2007) redescribed K. rossittensis on the basis of newly collected specimens from Slovakia and differentiated it from K. parva, another parasite of crucian carp and goldfish (Carassius spp.), by shape of the scolex (laterally more expanded in K. parva), a more anterior position of the first testes and vitelline follicles in $K$. rossittensis, and shape of the ovary, with posterior arms bent more inwards or even connected (inverted Ashaped) in K. rossittensis.

Szidat (1937) described another species of Bothrioscolex (= Khawia), B. dubius (=K. dubia), from the same host (crucian carp) and locality (Rossitten, Courland Spit, East Prussia). He based his description on only a very few specimens and admitted they closely resembled $B$. rossittensis ( $=$ K. rossittensis): "Die innere Organisation ähnelt hingegen wiederum der vorbeschriebenen Art, B. rossittensis so weitgehend, daß man glauben möchte, eine verkleinerte Ausgabe derselben Art vor sich zu haben." He distinguished the new species from $K$. rossittensis only by its markedly smaller size of the body: "Ohne Zweifel liegt aber hier eine besondere Art vor, die mit 5-6 $\mathrm{mm}$ Gesamtlänge und 2-2,5 mm Breite nur ein Viertel so lang wird wie Bothrioscolex rossittenis [sic!]" (Szidat 1937 - p. 783).

In fact, $K$. dubia is indistinguishable in its morphology from $K$. rossittensis and shares all the characteristics considered to be diagnostic for the latter species (see Oros and Hanzelová 2007, Oros et al. 2010; present study), including a triangular or cuneiform scolex, the ovary with posterior arms bent inwards, first testes and vitelline follicles beginning a short distance from the anterior extremity, almost at the same level as the anteriormost vitelline follicles, vitelline follicles completely absent alongside the ovary, and the size of the eggs $(45-49 \times 34-36 \mu \mathrm{m})$. 


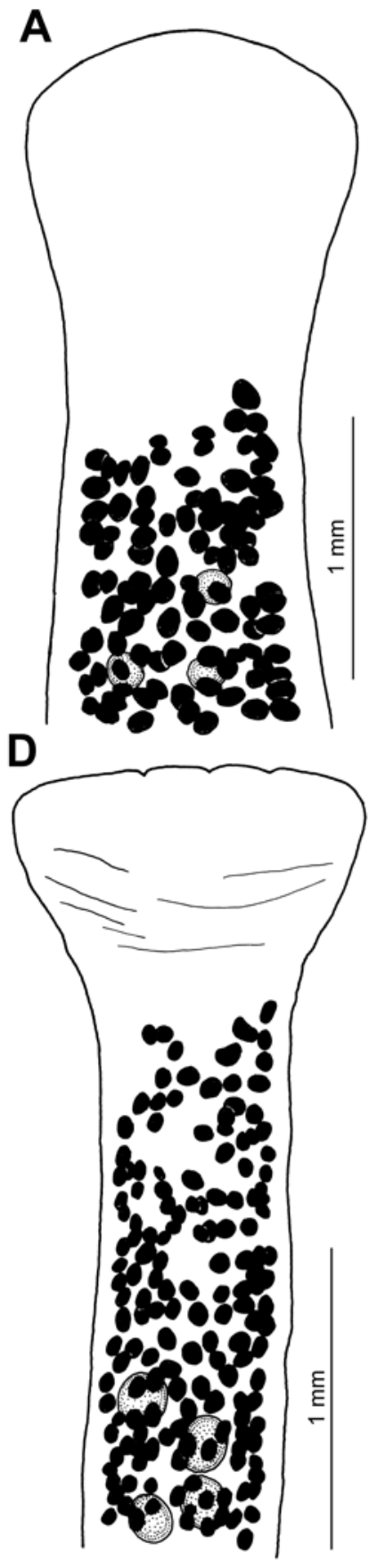

B

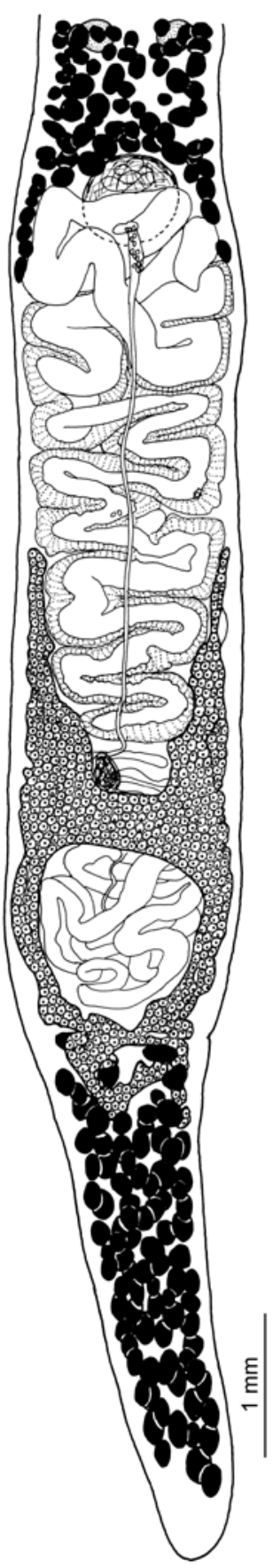

C

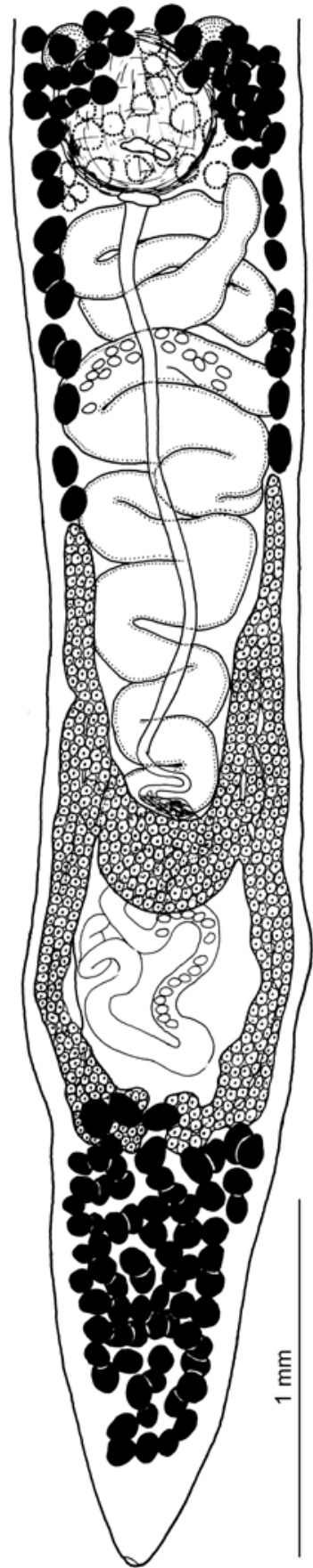

Fig. 6. Khawia rossittensis (Szidat, 1937) from Carassius auratus, Japan (A, C) (IPCAS C-339/2) and Slovakia (B, D) (ESMK 52/03, 205/06). A, D - anterior part of the body (note the anterior position of the first vitelline follicles, which begin just posterior to the neck region, anterior to the first testes); $\mathbf{B}, \mathbf{C}$ - posterior part of the body, ventral (note an inverted A-shaped ovary and the absence of vitelline follicles alongside the ovary).

Different length of the specimens studied by Szidat (1937) may have reflected individual, often density- or host-dependent size variability frequent among caryophyllidean tapeworms. Because of unreliability of the only alleged differential criterion between $K$. rossittensis and $K$. $d u$ bia (total body length), the latter species is invalidated as a new synonym of $K$. rossittensis.
Kamburov (1967) reported $K$. rossittensis from whiteeye bream, Ballerus sapa (Pallas), and roach, Rutilus rutilus (L.), from the Kiev water reservoir, Ukraine, but reliability of these records was already questioned by Dubinina (1987). 
Khawia saurogobii $\mathrm{Xi}$, Oros, Wang, $\mathrm{Wu}$, Gao et Nie, 2009

Material examined: Holotype, four paratypes and 11 vouchers from Saurogobio dabryi Bleeker, Yangtze River in Wuhan, China (IPCAS C-537/1).

Diagnosis (according to Xi et al. 2009a; $\mathrm{n}=10$ ): Body 9-19 mm long, maximum width $2.8 \mathrm{~mm}$ at level of middle part, tapering towards posterior end of body. Scolex afossate, truncated cuneiform-flabellate, with short creases on its anterior margin, $0.7-1.6 \mathrm{~mm}$ wide, markedly wider than neck $0.82-1.15 \mathrm{~mm}$ wide. Testes numerous, estimated number $320-450(\mathrm{n}=8)$, medullary, almost spherical, 108-281 × 105-230; anteriormost testes begin slightly posterior $(0.1-0.7 \mathrm{~mm})$ to anteriormost vitelline follicles; testicular field reaches to anterior margin of cirrus-sac. Cirrus-sac oval, 260-487 × 198-432. Ovary reticular rather than lobed, usually $\mathrm{H}$-shaped, rarely inverted A-shaped; arms 1.4-3.1 mm long and 0.5-1.4 mm wide. Seminal receptacle 174-199 × 82-93. Vitelline follicles cortical, begin $0.8-2.0 \mathrm{~mm}$ from anterior extremity; several (2-20) follicles present alongside preovarian loops of uterus; postovarian follicles extensive. Uterus tubular, forms numerous loops, overlapping posterior part of cirrus-sac. Uterine glands and common genital atrium present. Eggs oval, operculate, unembryonated, 47-62 $\times$ $28-37(\mathrm{n}=30$, intrauterine eggs).

Type host: Lizard gudgeon, Saurogobio dabryi Bleeker (Cyprinidae: Gobioninae).

Type locality: Yangtze River in Wuhan, China.

Type specimens: Helminthological Collection, Institute of Parasitology BC AS CR, České Budějovice, Czech Republic (holotype and paratypes - IPCAS C-537/1), The Natural History Museum London, United Kingdom (paratypes BMNH 2009.10.23.1-2), U.S. National Parasite Collection, Beltsville, Maryland, USA (paratypes - USNPC 102281 and 103382).

Definitive hosts: *Saurogobio dabryi, *Saurogobio dumerili Bleeker.

Life cycle: Not known.

Distribution: Asia (China).

Remarks. The species has been recently described based on tapeworms from gudgeons (Saurogobio spp.) from China (Xi et al. 2009a). It differs from congeneric species mainly in the following characteristics: (1) shape of the body, which tapers posteriorly from the end of the anterior third (Fig. 7A); (2) shape of the scolex, which is very short and wider than the neck, truncated cuneiformflabellate, with shallow superficial creases (Fig. 7B); (3) anteriormost extent of the vitelline follicles and testes, which begin immediately posterior to the neck region (Fig. 7A, B); and (4) the ovary with long posterior arms bent inwards or inverted A-shaped (Fig. 7C, D) (Xi et al. 2009a).

\section{Invalid species and taxa of uncertain status}

The following species have been placed in Khawia, but they actually belong to other caryophyllidean genera.

Khawia coregoni Kritscher, 1990 [= Caryophyllaeus laticeps (Pallas, 1781) - new synonym]

Material examined: Holotype, paratype and two vouchers, all immature, mounted as permanent preparations, and five small specimens in a vial, all from Coregonus wartmanni (Bloch) (vernacular name in Austria "Blaufelchen"), Mondsee, Austria, v. 1975 (E. Kritscher; NHMW Coll. Nos. 3042 - holotype, 3041a - other specimens as total mounts, 16176 - specimens in vial); tapeworms designated as "Khawia sp." from Coregonus sp., Mondsee, Austria, ii. 1969 (M. Rydlo; NHMW Coll. No. 4457).

Remarks. Khawia coregoni was inadequately described from immature, decomposed and deformed specimens found in whitefish, Coregonus wartmanni (Salmonidae: Coregoninae), from Mondsee in Austria (Kritscher 1990). The species was placed in Khawia, but no cross sections that would confirm the alleged cortical position of preovarian vitelline follicles were provided, which makes generic and even familial placement to the Lytocestidae uncertain. A true differential diagnosis of the new species from congeneric taxa was not provided, because Kritscher (1990) just mentioned some resemblance of $K$. coregoni with $K$. baltica, from which the former taxon should differ in its unspecified width. The validity of the new species was questioned even by its author himself, who wrote "(?) Khawia coregoni n. sp."

Poor quality of the material of $K$. coregoni, incompleteness of its morphological description and unreliability of some data presented by Kritscher (1990) cast doubts upon the validity of this species. Especially, the absence of postovarian vitelline follicles reported by Kritscher (1990) is very unusual, because all Palaearctic caryophyllideans possess invariably a well developed group of postovarian vitelline follicles (Protasova et al. 1990).

Examination of all available specimens of $K$. coregoni has shown that postovarian vitelline follicles are in fact present. It has also been observed that the cirrus-sac is situated near the ovary, which makes the uterine region of $K$. coregoni considerably short. This is a typical character of Caryophyllaeus Gmelin, 1790, whereas the preovarian uterine region is rather long in all species of Khawia (see Protasova et al. 1990 and present study - Figs. 1C, 3C, 4C, 6B, C).

Khawia coregoni is indistinguishable from Caryophyllaeus laticeps (Pallas, 1781), a common parasite of cyprinid fish in the Palaearctic Region (see Dubinina 1987, Scholz 1989, Protasova et al. 1990, Oros et al. 2010): (i) the scolex is flabellate, dorsoventrally flattened, 

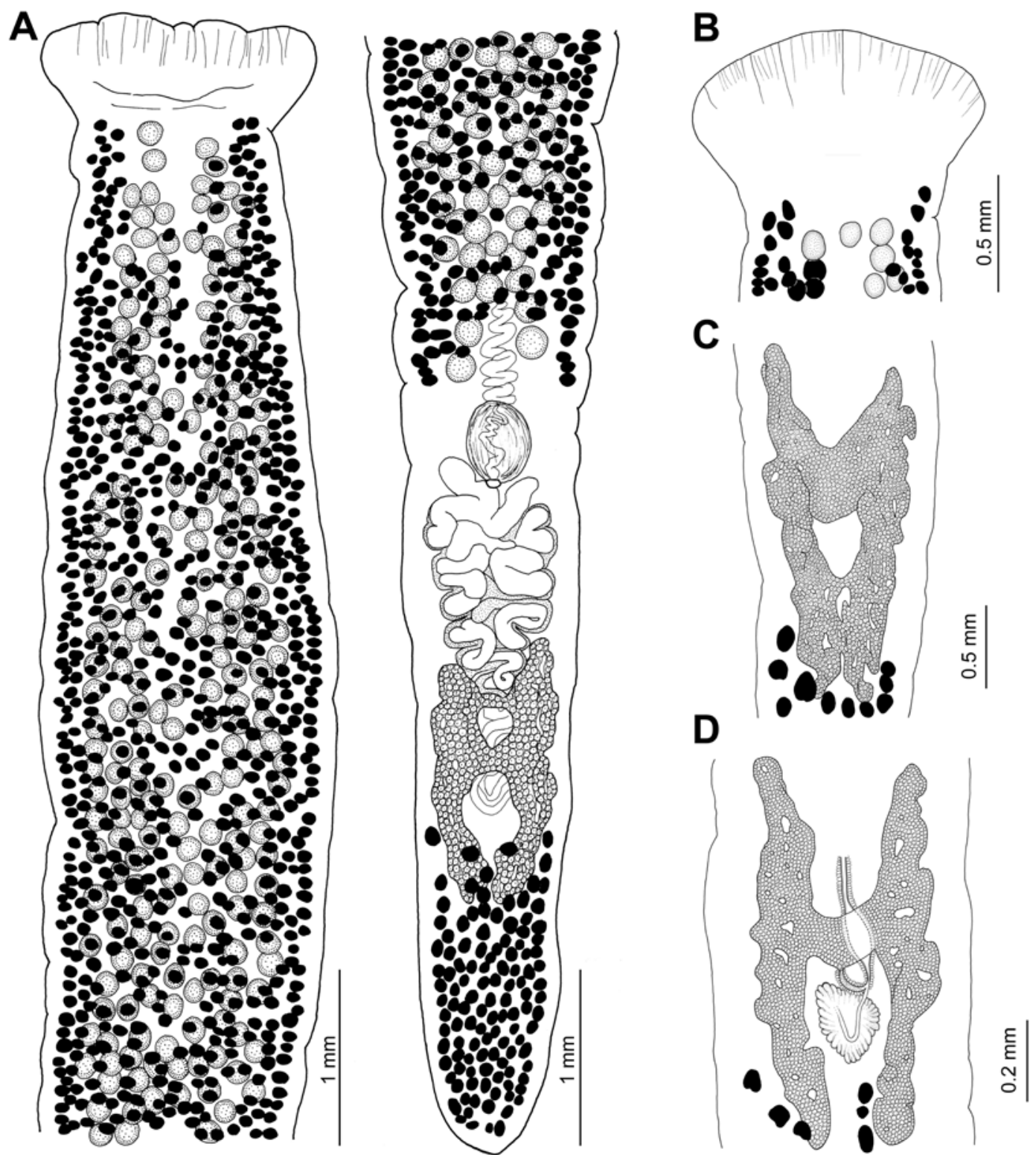

Fig. 7. Khawia saurogobii Xi, Oros, Wang, Wu, Gao et Nie, 2009 from Saurogobio dabryi, China (IPCAS C-537/1). A - holotype, ventral; B - scolex of paratype; C, D - outlines of the ovary (note inverted A-shaped ovary in C and H-shaped ovary in D).

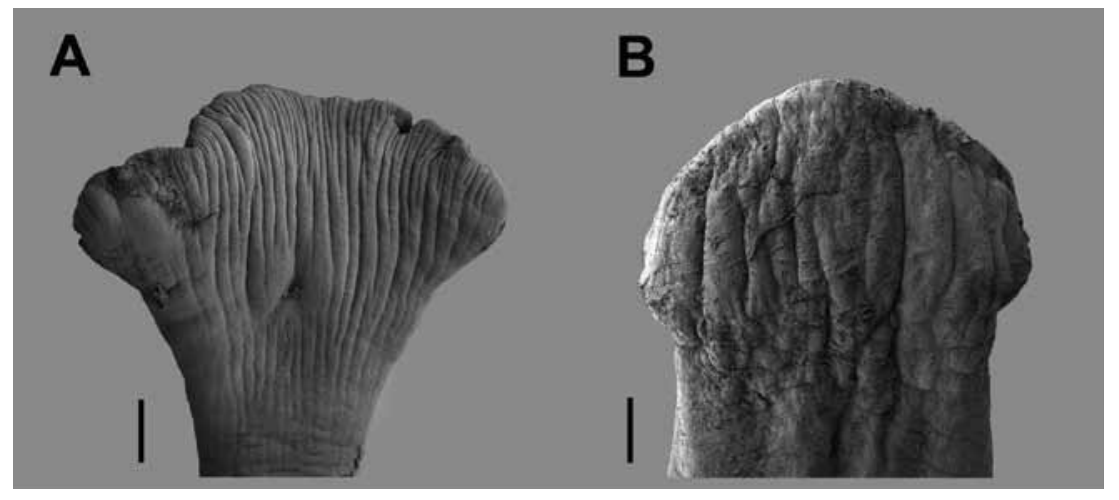

Fig. 8. Khawia baltica Szidat, 1941 from Tinca tinca, Czech Republic (A) and K. parva (Zmeev, 1936) from Carassius auratus, Far East, Russia (B). Scanning electron micrographs of scoleces. Scale bars: $200 \mu \mathrm{m}(\mathrm{A})$ and $100 \mu \mathrm{m}(\mathrm{B})$. 
considerably wider than the neck; (ii) the anterior margin of the scolex possesses short and shallow grooves; (iii) the first vitelline follicles start at a long distance posterior to the anterior extremity; (iv) the first testes begin far posterior to the anteriormost vitelline follicles; (v) the cirrus-sac is small, with its width representing much less than a half-width of the body at this level.

Based on this morphological similarity, K. coregoni is newly synonymized with $C$. laticeps, which occurs frequently in Austrian alpine lakes, including Mondsee, the type and only locality of $K$. coregoni (Rydlo 1985, Kritscher 1988, Jirsa et al. 2008).

\section{Khawia tenuicollis $\mathrm{Li}, 1964$ [= Atractolytocestus tenuicollis (Li, 1964) Xi, Wang, Wu, Gao et Nie, 2009}

Material examined: None; type specimens were reported to have been deposited in the Institute of Zoology, Academia Sinica in Peking (Beijing), China (Li 1964), but requests to Chinese researchers remained unanswered.

Remarks. Tapeworms described by $\mathrm{Li}$ (1964) as Khawia cyprini from common carp from Lake Wulasuhai in Inner Mongolia, China possess characteristics typical of Atractolytocestus Anthony, 1958, i.e., a bulboacuminate scolex, testes reaching posteriorly to the ovarian arms, and vitelline follicles forming uninterrupted lateral rows alongside the ovary (Mackiewicz 1994, Scholz et al. 2001). Therefore, Xi et al. (2009b) transferred the species to Atractolytocestus. This new combination is accepted by the present authors.

Khawia prussica (Szidat, 1937) Markevich, 1951 species incertae sedis

Synonym: Bothrioscolex prussicus Szidat, 1937.

Material examined: None (type specimens do not exist - see Calentine and Ulmer 1961).

Remarks. The species was briefly described by Szidat (1937) as Bothrioscolex prussicus from crucian carp (Carassius carassius) from East Prussia (now Russia Kaliningrad Region). Szidat (1937) did not make cross sections and thus familial and generic placement of the species, which has never been found since its original description, needs verification.

Bothrioscolex was synonymized with Khawia by Markevich (1951). Fotedar (1958) considered K. prussica to be a probable synonym of $K$. japonensis, but these species differ from each other in several morphological characteristics, especially shape of the scolex, position of the first vitelline follicles and testes, and the length of the uterine region.

In fact, $K$. prussica possesses a short uterine region and preovarian vitelline follicles reach almost to the ovarian arms, which are characteristics typical of species of Caryophyllaeus (see Protasova et al. 1990, Mackiewicz 1994), and it may belong to this genus. In contrast, its placement in Khawia is not justified by its morphology and thus $K$. prussica is tentatively considered species incertae sedis.

\section{Interrelationships of Khawia species based on molecular data}

Sequences of two nuclear ribosomal and two mitochondrial genes of each of seven Khawia species were obtained. As expected, mitochondrial genes nad3 and cox 1 showed greater variability at the nucleotide level than the nuclear genes. Of the total number of 2,072 ssrDNA and 1,584 lsrDNA alignable positions, 123 (5.9\%, ssrDNA) and $210(13.3 \%$, lsrDNA) were found variable of which 72 (ssrDNA) and 118 (lsrDNA) were parsimony-informative. The $345 \mathrm{bp}$ long $\operatorname{nad} 3$ and $675 \mathrm{bp}$ long part of cox 1 offered $227(65.8 \%$, nad3) and $344(51.0 \%$, cox 1$)$ variable and 186 (nad3) and 297 (cox 1$)$ parsimonyinformative characters.

Phylogenetic relationships within Khawia based on analysis of nuclear ribosomal and mitochondrial datasets are summarized in Fig. 9. On the whole, analyses of nucleotide alignments of both nuclear ribosomal and mitochondrial datasets (analyses of nucleotide alignments of nad 3 and cox 1 not shown), similarly as the concatenated dataset of all genes, revealed completely identical topology (Fig. 10). The phylogram based on the analysis of amino acids (Fig. 9 right) revealed a highly similar topology, the only difference to the estimates from nucleotide alignments being the sister group status of Khawia sinensis from Slovakia and Japan.

The molecular analysis has shown that species of Khawia form three major groups and this grouping largely corresponds to their fish definitive hosts. Five species from common carp, crucian carp, goldfish and gudgeons, i.e., (K. japonensis (K. rossittensis $+K$. parva)) (K. sinensis $+K$. saurogobii), grouped together, whereas $K$. armeniaca from barbels (Barbinae) and $K$. baltica from tench (Tinca) formed separate clades (Fig. 10). In contrast, geographical distribution (Europe versus East Asia) does not seem to play a crucial role in grouping individual taxa.

\section{Interrelationships of Khawia species based on morphological data}

The cladistic analysis found 19 equally parsimonious trees with the following tree statistics: tree length $=23$, $\mathrm{CI}=0.56, \mathrm{RI}=0.50$. A majority rule consensus of these 19 trees is shown in Fig. 11. Resulting tree based on 11 morphological characters did not provide good resolution of phylogenetic relationships because of polytomies and/ or weak support of more resolved clades (K. armeniaca with $K$. parva and $K$. rossittensis - Fig. 11). In addition, the tree was incongruent with that inferred from molecular data (Figs. 9, 10), except for grouping two parasites of crucian carp and gold fish, $K$. parva and $K$. rossittensis, in the same, yet weakly supported clade (Fig. 11). 




Fig. 9. Evaluation of phylogenetic relationships within Khawia by maximum likelihood method based on nuclear ribosomal (ssrDNA and D1-D3 lsrDNA; left) and mitochondrial ( $\mathrm{ad} 3$ and cox1; right) datasets. Branch labels based on bootstrap values estimated in RAxML (100 repetitions). Both trees are unrooted.

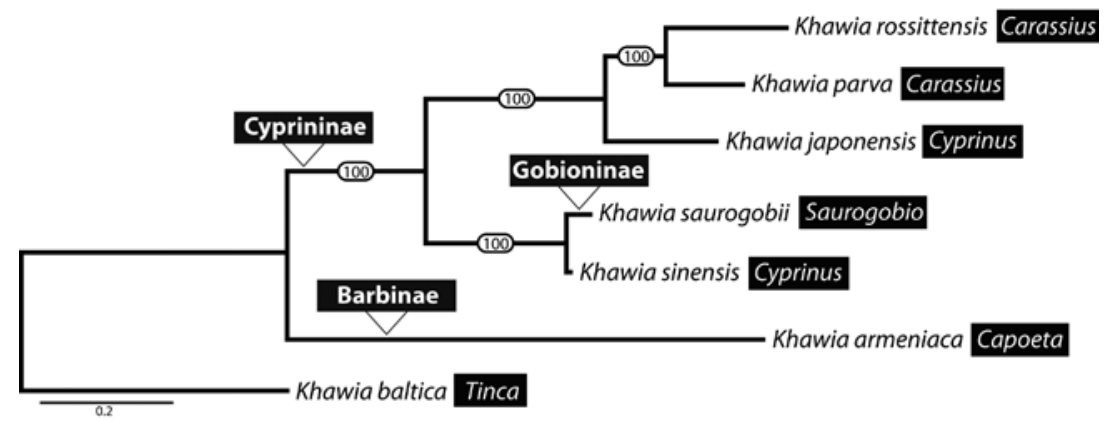

Fig. 10. Interrelationships of seven Khawia species representatives based on maximum likelihood analysis of concatenated dataset (ssrDNA, D1-D3 lsrDNA, nad3 and cox1) with allocated definitive host groups (genera of type hosts). Branch labels based on bootstrap values estimated in RAxML (100 repetitions). Unrooted tree.

\section{DISCUSSION}

\section{Species composition}

The present revision summarizes data on species of Khawia accumulated since the end of the 1980's, when the morphology, life cycles and seasonality in the occurrence and maturation of two Khawia species parasitic in common carp and tench, respectively, were studied (Scholz 1989, 1991a, b, 1993, Scholz et al. 1990). Thereafter, extensive materials of Khawia tapeworms have been collected by the present authors in the Czech Republic, Japan, Portugal, Russia, Slovakia and Vietnam or was provided by their co-workers from Italy, Japan, Russia, Switzerland, UK and USA. Specimens deposited in principal helminthological collections in Europe, Russia and USA were also examined.

New sampling of extensive quantity of materials of several species and their fixation with standardized methodology (hot formalin for morphological, histological and SEM studies - Oros et al. 2010; 96\% non-denaturated ethanol for DNA analyses - Brabec et al. 2006) made it possible to critically review the species composition of one of the most specious genera of caryophyllidean tapeworms (as many as 17 nominal taxa) and to assess their phylogenetic relationships inferred from sequences of two nuclear and two mitochondrial genes. As a result of this comparative study, the total number of species of Khawia consid-

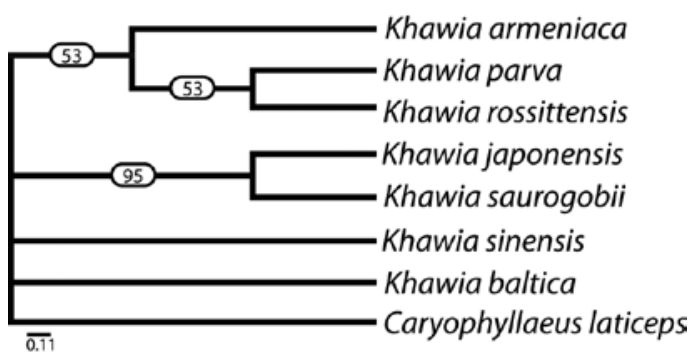

Fig. 11. A $50 \%$ majority rule consensus tree inferred from 19 equal-length trees based on 11 morphological characters (see Appendix). Numbers at the nodes show majority rule values (percentages).

ered to be valid is reduced to seven, whereas eight taxa are newly synonymized and one new combination first proposed by Xi et al. (2009b) is confirmed. A similar reduction in the number of valid species has been proposed for caryophyllidean tapeworms parasitic in catfish in the Indomalayan Region (Ash et al. 2011, 2012) as well as species of Wenyonia Woodland, 1923, parasites of Synodontis catfish in Africa (Schaeffner et al. 2011).

Taxonomic inflation, i.e., descriptions of a high number of doubtful taxa, which have later been found as invalid, is caused, among others, by a little attention paid to appropriate processing of the worms studied. Decomposed, deformed or even incomplete specimens have been used for 
taxonomic descriptions, which thus contained incorrect data. Intraspecific morphological variability of worms is often not taken into account when new taxa are proposed. This was apparently the case of two species of Khawia described from the same species of barbels in Iraq (K. barbi and $K$. lutei) and all four taxa from carp proposed by Chinese authors, who used strongly flattened, apparently deformed specimens for erection of several new species of Khawia and Tsengia. Mackiewicz (1981a) and recently Ash et al. (2011) briefly summarized other problems related to continuing publication of unreliable descriptions of new caryophyllidean taxa in the Indomalayan Region, but their remarks and recommendations are applicable to the taxonomy of helminths in general.

Type specimens and/or ethanol-fixed material of several Khawia species were not available, including two species described in Bothrioscolex by Szidat (1937), which have never been found since their description. Therefore, the proposed synonymies were based on morphological data provided in the original descriptions, which could not be confirmed by a study of their types or supported by molecular data. In contrast, ethanol-fixed material of seven Khawia species considered to be valid was available, which enabled us to assess their phylogenetic relationships.

\section{Phylogenetic relationships}

The molecular analysis of four genes of seven species of Khawia, similarly as the concatenated dataset of all genes, revealed a completely identical topology. This is a strong argument to assume that the trees demonstrated in Fig. 9 reflect the actual phylogenetic relationships of Khawia species. The genus split into three groups, i.e., the $K$. baltica and $K$. armeniaca clades, each formed by a single species, and the "carp" clade, which comprises five species (Fig. 9). Each group is characterized by its fish definitive hosts: tench, barbels and remaining cyprinid hosts, in particular carps (common and crucian carp and goldfish), respectively. This grouping based on fish hosts is valid for the main clades, but both species specific to common carp, $K$. japonensis and $K$. sinensis, are not closely related, unlike $K$. parva and $K$. rossittensis from crucian carp and goldfish.

A phylogenetic tree based on 11 morphological characters (Appendix) was almost completely incongruent with the tree inferred from molecular data, which indicates that morphological traits may be homoplastic, such as overall shape of the body and scolex, and anterior extent of vitelline follicles and their relationships with the first testes. The most evident conflict between morphological and molecular data represented the position of $K$. armeniaca, which formed a separate clade in molecular tree, but appeared as a sister taxon to the clade with two Khawia species from Carassius (Figs. 10, 11), and mutual position of $K$. sinensis and K. saurogobii. These two species are morphologically markedly different (Fig. 11) but, surprisingly, sequences of their nuclear and mitochondrial genes were very similar, especially between Chinese isolates (Figs. 9, 10).

A similar conflict between higher-level phylogenies (genera and families) inferred from morphological characters (Oros et al. 2008) and those based on comparative sequences of DNA data (Olson et al. 2008) indicate artificial character of the present familial classification, which is based on the position of the inner longitudinal musculature in relation to vitelline follicles (Mackiewicz 1994).

In the present study, congruency between molecular and morphological data was found only in $K$. baltica, which is phenotypically different from the remaining species of Khawia mainly in the shape of the scolex and presence of vitelline follicles alongside the ovary. Molecular data also supported a distant position of $K$. baltica from other Khawia species.

\section{Conflict of morphological and molecular data and species delimitation}

Conflict between morphological and genetic data represents one of the most important problem of the current taxonomy and systematics of parasitic animals, with serious practical consequences, such as artificial classification, incorrect nomenclature and false diagnostics of medically and veterinary important pathogens. Two basic types of incongruence of DNA- and morphology-based information were found in the present study: (1) genetic similarity of morphologically dissimilar taxa; (2) morphological similarity of species with high nucleotide divergence, which may represent sibling species.

The first case is represented by $K$. sinensis, especially specimens from common carp in China, because its nucleotide divergence from morphologically well differentiated $K$. saurogobii parasitic in unrelated fish host was very low (Fig. 9). It can be assumed that the latter species, after switching to a new fish host (gudgeons of the genus Saurogobio), underwent morphological divergence (see $\mathrm{Xi}$ et al. 2009a) as a result of ongoing sympatric speciation, but this process has not been accompanied by corresponding nucleotide changes. No data on the effect of fish host, i.e., its ecology, including feeding behaviour, and physiology of its digestive tract, on morphological evolution of caryophyllidean tapeworms are available, but influence of the host on parasite's growth and development has been postulated (Dogiel et al. 1958, Smyth and McManus 1988), including fish tapeworms (Molnár 1968, 1977, Pool and Chubb 1985, Pool 1987).

The second case is represented by samples of Khawia tapeworms from barbels from a large distribution area (Portugal, Morocco, Egypt, Uganda, Tanzania, Armenia, Iraq and Iran), which were morphologically rather similar 
and shared the morphological characteristics considered species-specific for $K$. armeniaca. In contrast, sequences of specimens from the type locality (Armenia) and from the westernmost point of its distribution area (Portugal) were markedly different, thus suggesting possible existence of cryptic or sibling species. The information on genetic variability of Khawia tapeworms from different hosts (Barbinae) and geographical regions, especially northern and equatorial Africa, is necessary before any taxonomic action is proposed.

\section{Host spectrum and geographical distribution}

Khawia armeniaca exhibits by far the widest spectrum of fish definitive hosts, which include several species of barbels (Barbus, Capoeta, Carasobarbus, Luciobarbus), but also salmoniform fish (Salmo ischchan, Coregonus lavaretus). Other species of Khawia are host-specific (stenoxenous or oioxenous) because they parasitize only one or very few closely related fish hosts. Some species, such as $K$. sinensis and $K$. japonensis in common carp, can infect the same fish host simultaneously.

The original distribution of some species, such as $K$. baltica, $K$. japonensis and $K$. parva, was probably limited to small areas, whereas others, e.g., K. armeni$a c a$ and $K$. rossittensis, are widely distributed. Nevertheless, the current distribution area of several species of Khawia has been considerably expanded as a result of man-made introduction of uninspected stocks of fish (Hoole 1994). The distribution area of $K$. sinensis was originally limited to East Asia (China, Japan, Russian Far East), but this tapeworm was introduced to Europe and North America in the 20th century (Oros et al. 2009). Recently, another Khawia species of Asian origin, $K$. japonensis, has been introduced to Europe (northern Italy) (Scholz et al. 2011).

\section{Importance of Khawia tapeworms}

Except for $K$. sinensis, almost no data on the veterinary importance and pathology of Khawia spp. are available. Khawia sinensis was considered a pathogenic parasite of cultured carp after its introduction to the European part of the former Soviet Union, Eastern and Central Europe in the 1950's and 1960's (Kulakovskaya and Krotas 1961, Musselius et al. 1963, Bauer et al. 1973, Körting 1975, Hoole 1994). Some studies demonstrated that $K$. sinensis caused serious inflammations of the intestine of the fish host and mechanical destructions of its intestinal epithelium; as a consequence, erythrocyte number and leukocyte activity decreased (Jara and Szerow 1981, Morley and Hoole 1995, 1997). Several cases of mortality of carp fry were also documented in Europe (see Williams and Jones 1994 for review), whereas other studies did not confirm pathogenic effect of the tapeworm even on heavily infected fish hosts (Weirowski 1979, Chubb and Yeomans
1995). Currently, the veterinary importance of $K$. sinensis seems to have decreased (Oros et al. 2009).

Unique morphology, ultrastructure, life cycles and some genetic and cytogenetic characteristics (e.g., presence of divergent intragenomic ITS copies, ITS paralogues - I. Král'ová-Hromadová, unpubl. data; Orosová et al. 2010), still unclear evolutionary history (Mackiewicz 1981b, 2003, Olson et al. 2001, 2008) and possible ongoing divergence of morphological and genetic (molecular) evolution in some species make Khawia tapeworms an interesting model for evolutionary, genetic and comparative studies. The veterinary importance and pathogenic potential of these tapeworms should also not be underestimated, especially in relation to continuous import of carp and other cyprinid fish to numerous countries outside of their original distribution area (Scholz et al. 2011).

\section{Concluding remarks}

The present paper represents the first complex study, in which morphological and molecular data were used simultaneously for a critical revision of the species composition of a specious genus of caryophyllidean tapeworms. A multidisciplinary approach applied to a systematic study of museum materials and newly collected, properly fixed specimens enabled us to obtain a robust dataset necessary for clarification of the systematic status of all nominal taxa and for assessment of their phylogenetic relationships.

Revision of Khawia is part of ongoing research on the systematics and phylogeny of monozoic tapeworms and has been, or will be, followed by similar critical studies on most specious groups of these parasites of siluriform and cypriniform fish (Oros et al. 2010, Ash et al. 2011, 2012, Schaeffner et al. 2011). Molecular tools and updated morphological methods, including scanning electron microscopy, will also be used in revision of a possible species complex of the oldest fish tapeworm, the caryophyllidean Caryophyllaeus laticeps (Pallas, 1781), a parasite of wide spectrum of cypriniform fishes in the Palaearctic Region.

As a practical outcome of the present study, a key to species of Khawia is provided to facilitate identification of these cestodes on the basis of their gross morphology and some internal characteristics.

\section{Key to the identification of Khawia species}

The key is based primarily on gross morphology and a few characteristics of the scolex and genital organs, such as the posterior extent of vitelline follicles and shape of the ovary. However, species identification should be verified using individual species diagnoses provided in the redescriptions above and in Oros et al. (2010), who studied scolex morphology. Spectrum of fish hosts may also help as an additional differential criterion, because most species exhibit narrow host specificity. 
1 Ovary butterfly-shaped, i.e., with short, but wide lateral arms (Fig. 2D-F); postovarian vitelline follicles not numerous (less than 110), few solitary vitelline follicles located around posterior ovarian arms (Fig. 2D-F); scolex semibulbate, wider than neck, with entire anterior margin (Fig. 2A-C). Parasite of barbels (Barbinae)

... Khawia armeniaca (Cholodkovsky, 1915) (Fig. 2)

- Ovary H- or inverted A-shaped, with long, relatively narrow lateral arms; postovarian vitelline follicles numerous (more than 110), surrounding posterior ovarian arms (e.g., Fig. 1C)

2 Scolex fimbriate, i.e., with fimbriae or small lobes on its front edge (Figs. 1A, B, 4A, D, F) ................. 3

- Scolex of other shape, without fimbriae or small lobes on its front edge

4

3 Scolex festoon-shaped, with deep folds, much wider than a long neck region (Fig. 1A, B); first testes begin at a large distance posterior to first vitelline follicles, both beginning far posterior from the anterior extremity (Fig. 1A); vitelline follicles absent or very few alongside preovarian loops of the uterus (Fig. 1C, D). Parasite of common carp (Cyprinus carpio) and other cyprinids (Ctenopharyngodon, Hemibarbus) ................. Khawia sinensis Hsü, 1935 (Fig. 1)

- Scolex cuneifimbriate, with creases formed by fimbriae or small lobes on the front edge, only slightly wider than a very short neck region (Fig. 4A, D, F); first testes begin slightly anterior to, or at same level as, first vitelline follicles, both being situated closely posterior to the scolex (Fig. 4A, D, F); vitelline follicles present alongside preovarian loops of the uterus (Fig. 4C, E). Parasite of common carp (C. carpio) .. ........ Khawia japonensis (Yamaguti, 1934) (Fig. 4)

4 Body spindle-shaped, with maximum width at the anterior third or half of the body (Fig. 7A); scolex truncated cuneiform-flabellate, with short creases on its anterior margin, very short (Fig. 7B); vitelline follicles absent alongside uterine loops (Fig. 7A); first testes and vitelline follicles begin at a short distance posterior to the anterior extremity (Fig. 7B). Parasite of gudgeons (Gobiinae: Saurogobio)

...... Khawia saurogobii Xi, Oros, Wang, Wu, Gao et Nie, 2009 (Fig. 7)

- Body elongate, with maximum width at the posterior half of the body or at the scolex level; scolex longer (Figs. 3A, B, 5A, B, 6A, D); testes and vitelline follicles begin at a distance posterior to the anterior extremity

5

5 Scolex flabellate, markedly wider than the neck, with small wrinkles along the front edge (Fig. 3A, $\mathrm{B})$; vitelline follicles present also alongside ovarian arms (Fig. 3C, D). Parasite of tench (Tinca tinca) ... Khawia baltica Szidat, 1941 (Fig. 3)
- Scolex cuneiform or of triangular shape (Figs. 5A, B, $6 \mathrm{~A}, \mathrm{D})$; vitelline follicles absent alongside ovarian arms. Parasites of crucian carp and goldfish (Carassius) .. 6

6 Scolex cuneiform, laterally extended (Fig. 5A, B); vitelline follicles begin at a distance posterior to the scolex (Fig. 5A, B); posterior ovarian arms only slightly bent inwards (Fig. 5C)

Khawia parva (Zmeev, 1936) (Fig. 5)

- Scolex of triangular shape or cuneiform; vitelline follicles begin just posterior to the scolex (Fig. 6A, D); ovary with posterior ovarian arms bent inwards (Fig. 6C) or inverted A-shaped, i.e., with posterior arms connected (Fig. 6B)

Khawia rossittensis (Szidat, 1937) (Fig. 6)

\section{Appendix. Morphological characters and their coding}

1. Body (overall shape): $0=$ widest at the anterior extremity (scolex); $1=$ widest at the anterior third of the body; 2 = widest at the posterior third of the body, usually at the level of the cirrus-sac.

2. Scolex (overall shape): $0=$ flabellate; $1=$ bulbate/ semibulbate; 2 = slightly wider than neck.

3. Scolex (anterior margin): $0=$ fimbriate or with folds; $1=$ entire (without folds, fimbriae or small lobes).

4. Testes (posterior extent): $0=$ posteriormost testes anterior to cirrus sac; 1 = posteriormost testes may reach alongside cirrus-sac.

5. Ovary (shape): $0=$ H-shaped, bilobed; $1=$ with posterior lobes bent inwards (inverted A-shaped).

6. First vitelline follicles (position): $0=$ begin at distance posterior to the scolex; 1 = begin at the base of the scolex.

7. First vitelline follicles (relation to first testes): 0 = first vitelline follicles pretesticular; $1=$ first vitelline follicles post-testicular or vitelline follicles and testes start at approximately same level.

8. Vitelline follicles (alongside preovarian uterine loops): $0=$ absent or very few (just individual follicles present, not forming a continuous line); $1=$ present (continuous line).

9. Vitelline follicles (alongside ovary): $0=$ absent; $1=$ present.

10. Postovarian vitelline follicles: $0=$ few; $1=$ numerous.

11. Egg size (length): $0=$ eggs larger than $50 \mu \mathrm{m}$; $1=$ eggs smaller than $50 \mu \mathrm{m}$.

Acknowledgments. The authors are deeply indebted to two anonymous reviewers, to M. Borovková and B. Škoríková for excellent technical help, R. Kuchta (all IPCAS, České Budějovice) for invaluable help during sampling trips to Japan and Vietnam in 2007 and 2010, respectively, and L. Burik, Košice for technical assistance in the field. The following persons kindly provided materials of Khawia tapeworms for this study: S. Abdullah, Iraq (K. armeniaca), J.S. Mackiewicz, USA 
(K. iowensis), L.G. Poddubnaya, Russia (K. armeniaca), A. Saraiva, Portugal (K. armeniaca), M. Shedko, Russia (K. parva) and M. Urabe, Japan ( $K$. rossittensis). Authorities of the following museums made it possible to study types and voucher specimens of Khawia species: U.S. National Parasite Collection, Beltsville, USA (E.P. Hoberg and P. Pilitt); Natural History Museum, Geneva, Switzerland (J. Mariaux and A. de Chambrier); The Natural History Museum, London (D.I. Gibson, D.T.J. Littlewood and E. Harris); Institute of Parasitology, České Budějovice (F. Moravec); Museum of East Slovakia, Košice (J. Duchoň); GELAN, Moscow (E.N. Protasova and L.V. Filimonova); and Zoological Institute of the Russian Academy of Sciences, Sankt Petersburg (A. Galkin). Samples from Japan were taken during short stays of the senior author (TS) in Japan in 2001 and 2007, supported by Research Projects K00-05 and S06-02 of the Lake Biwa Museum, directed by M.J. Grygier. Stays of TS and MO at The Natural History Museum in London and Natural History Museum in Vienna were enabled by the EU programme SYNTHESYS (projects GB-TAF-4782, GB-TAF-2354 and ATTAF-411, respectively). This study was financially supported by the Grant Agency of the Czech Republic (No. 524/08/0885), Institute of Parasitology (Nos. Z60220518 and LC 522), Grant Agency VEGA (No. 2/0014/10), Slovak Research and Development Agency (No. LPP-0171-09) and the National Science Foundation, USA (PBI award Nos. 0818696 and 0818823). The publication has been realized within a frame of the project Centre of Excellence for Parasitology (Code ITMS: 26220120022) based on the support of the Operational Programme "Research $\&$ Development" funded from the European Regional Development Fund (rate 0.3).

\section{REFERENCES}

Al-KalaK S.N., Rahemo Z.I.F. 2003: Morphological and histological studies on Khawia lutei sp. n. (Cestoda: Lytocestidae) a parasite of hemri, Barbus luteus, in Iraq. Riv. Parassitol. 20: 25-33.

Ash A., Scholz T., Oros M., Kar P.K. 2011: Tapeworms (Cestoda: Caryophyllidea), parasites of Clarias batrachus (Pisces: Siluriformes) from the Indomalayan Region. J. Parasitol. 97: 435-459.

Ash A., Scholz T., Oros M., Kar P.K. 2012: Cestodes (Caryophyllidea) of the stinging catfish Heteropneustes fossilis from Asia. J. Parasitol. 98. (In press.)

Bazsalovicsová E., Králová-Hromadová I., Štefka J., Scholz T., Hanzelová V., Vávrová S., Szemes T., Kirk R. 2011: Population study of Atractolytocestus huronensis (Cestoda: Caryophyllidea), an invasive parasite of common carp introduced to Europe: mitochondrial cox1 haplotypes and intragenomic ITS2 variants. Parasitol. Res. 109: 125-131.

Bauer O.N., Musselius V.A., Strelkov Y.A. 1973: Diseases of Pond Fishes. Israel Programme for Scientific Translations, Jerusalem, $220 \mathrm{pp}$.

BEGOYAN ZH.T. 1977: [Data on morphogenesis of Khawia armeniaca (Cholodkowsky, 1915) during its development in the definitive hosts.] Biol. Zh. Arm. 30: 79-84. (In Russian.)

Brabec J., Kuchta R., Scholz T. 2006: Paraphyly of the Pseudophyllidea (Platyhelminthes: Cestoda): circumscription of monophyletic clades based on phylogenetic analysis of ribosomal RNA. Int. J. Parasitol. 36: 1535-1541.

Calentine R.L., Ulmer M.J. 1961: Khawia iowensis n. sp. (Cestoda: Caryophyllaeidae) from Cyprinus carpio L. in Iowa. J. Parasitol. 47: 795-805.

de Chambrier A. 2001: A new tapeworm from the Amazon, Amazotaenia yvettae n. gen., n. sp. (Eucestoda: Proteocephalidea) from the siluriform fishes Brachyplatystoma filamentosum and B. vaillanti (Pimelodidae). Rev. Suisse Zool. 108: 303-316.

de Chambrier A., Sène A., Mahmoud Z., Mariaux J., Scholz T. 2008: Sandonella sandoni (Lynsdale, 1960), an enigmatic and morphologically unique cestode parasitic in the osteoglossiform fish Heterotis niloticus in Africa. J. Parasitol. 94: 202-211.

Chervy L. 2002: The terminology of larval cestodes or metacestodes. Syst. Parasitol. 52: 1-33.

Chervy L. 2009: Unified terminology for cestode microtriches: a proposal from the international workshops on cestode systematics in 2002-2008. Folia Parasitol. 56: 199-230.
Cholodkovsky N. 1915: Notes helminthologiques. Ann. Mus. Zool. Acad. Sci. Russ., Petrohrad 20: 164-166.

Chubb J.C., Eiras J.C., Saraiva A. 1997: Khawia baltica (Cestoidea: Caryophyllidea) from Barbus barbus bocagei from some rivers in northern Portugal. Folia Parasitol. 44: 131-138.

ChubB J.C., Yeomans W.E. 1995: Khawia sinensis Hsü, 1935 (Cestoda: Caryophyllidea), a tapeworm new to the British Isles: a treat to carp fisheries? Fish. Manag. Ecol. 2: 263-277.

Demshin N.I. 1975: [Oligochaeta and Hirudinea as Intermediate Hosts of Helminths.] Nauka, Novosibirsk, 190 pp. (In Russian.)

Demshin N.I. 1978: [Biology of Khawia japonensis (Caryophyllidea, Cestoda) - a parasite of the Amur carp.] Parazitologiya 12: 493-496. (In Russian.)

Demshin N.I. 1984: [On the biology of Caryophyllaeus fimbriceps Annenkova-Chlopina, 1919 and Khawia parva (Zmejev, 1936) (Caryophyllidea, Cestoda) - parasites of cyprinid fish.] Parasites of animals and plants, AN SSSR, pp. 63-70. (In Russian.)

Demshin N.I., DvoryadKin V.A. 1980: [Biology of Khawia sinensis Hsü, 1935 (Caryophyllidea, Cestoda) - a parasite of Amur carp.] Gidrobiol. Zh. 16: 77-82. (In Russian.)

DinNiK J.A. 1933: Les vers parasitiques des poissons du lac de Sevan. Trudy Sevanskoi Ozernoi Stantsii 4: 105-132. (In Russian, with French and Armenian summaries.)

Dogiel V.A., Petrushevskil G.K., Polyanski Yu.I. 1958: [Basic Problems of the Parasitology of Fish.] Izd. Leningradskogo Universiteta, Leningrad, 364 pp. (In Russian, with German summary.)

Drummond A.J., Ashton B., Cheung M., Heled J., Kearse M., Moir R., Stones-Havas S., Thierer T., Wilson A.C. 2009: Geneious ver. 4.8. Available from http://www.geneious.com/.

Dubinina M.N. 1971: [Cestodes from fishes of the Amur River basin.] Parazitol. Sb. 255: 77-119. (In Russian.)

Dubinina M.N. 1987: [Class tapeworms - Cestoda Rudolphi, 1808.] In: O.N. Bauer (Ed.), [Key to the Parasites of Freshwater Fishes of the USSR.], Nauka, Leningrad, pp. 5-76. (In Russian.)

Ergens R., Gussev V.A., Izyumova N.A., Molnár K. 1975: Parasite fauna of fishes of the Tisa River basin. Rozpravy ČSAV, mat. a př́r. vědy, Academia, Praha, 85, 117 pp.

Fotedar D.N. 1958: On a new caryophyllaeid cestode, Adenoscolex oreini gen. et. sp. nov. from fresh-water fish in Kashmir, and a note on some related genera. J. Helminthol. 32: 1-16.

Gibson D.I., Valtonen E.T. 1983: Two interesting records of tapeworms from Finnish waters. Aquilo Serie Zool. 22: 45-49. 
Hoffman G.L. 1999: Parasites of North American Freshwater Fishes. Second Edition. Comstock Publishing Associates, Cornell University Press, Ithaca \& London, 539 pp.

Hoole D. 1994: Tapeworm infections in fish: past and future problems. In: A.W. Pike and J.W. Lewis (Eds.), Parasitic Diseases of Fish. Samara Publishing Limited, Tresaith, Wales, UK, pp. 119-140.

Hsü H.F. 1935: Contribution à l'étude des cestodes de Chine. Rev. Suisse Zool. 42: 485-492.

JANISZEWSKA J. 1954: [Caryophyllaeidae of Europe with focus on Poland]. Prace Wroclawskiego towarzystva naukowego, Seria B., 66, 74 pp. (In Polish.)

JARA Z., Szerow D. 1981: Histopathological changes and localisation of tapeworm Khawia sinensis Hsü, 1935 in the intestine of carps (Cyprinus carpio L.). Wiad. Parazytol. 27: 695-703.

Jirsa F., Konecny R., Frank C. 2008: The occurrence of Caryophyllaeus laticeps in the nase Chondrostoma nasus from Austrian rivers: possible anthropogenic factors. J. Helminthol. 82: 53-58.

Kamburov G.G. 1967: [On the dynamics of tapeworms of Kiev water reservoirs.] Probl. Parazitol. Naukova dumka, Kiev, pp. 468-471.

KöRting W. 1975: Aspekte zum Bandwurmbefall der Fische. Die Bedeutung der Parasiten für die Produktion von Süsswasserfischen. Fisch Umwelt 1: 81-87.

Králová-Hromadová I., Štefka J., Špakulová M., Orosová M., Bombarová M., Hanzelová V., Bazsalovicsová E., Scholz T. 2010: Intra-individual internal transcribed spacer 1 (ITS1) and ITS2 ribosomal sequence variation linked with multiple rDNA loci: a case of triploid Atractolytocestus huronensis, the monozoic cestode of common carp. Int. J. Parasitol. 40: 175-181.

Kritscher E. 1988: Die Fische des Neusiedlersees und ihre Parasiten. VI. Cestoidea. Ann. Natuhist. Mus. Wien, 90/B: 183-192.

KRITSCHER E. 1990: Biologische und parasitologische Untersuchungen an Coregonus wartmanni (Bloch, 1782) (Pisces, Salmonidae) aus dem Mondsee (Oberösterreich). Ann. Naturhist. Mus. Wien 91/B: 225-241.

Kulakovskaya O.P. 1961: On the fauna of the Caryophyllaeidae (Cestoda, Pseudophyllidea) of the USSR. Parazitol. Sb. Zool. Inst. AN SSSR 20: 339-354.

Kulakovskaya O.P. 1962: [Development of tapeworms (Caryophyllaeidae, Cestoda) in intermediate hosts.] Zool. Zh. 7: 986992. (In Russian.)

Kulakovskaya O.P. 1963. [On the biology and life cycle of the tapeworm Khawia sinensis Hsü, 1935.] Probl. Parazitol. 2: 200205. (In Russian.)

Kulakovskaya O.P. 1964: Life cycle of Caryophyllaeidae (Cestoda) in the conditions of western Ukraine. Cesk. Parasitol. 11: $177-185$.

Kulakovskaya O.P. 1969: [Cestodes of freshwater fish of the Ukraine SSR.] Summary of D.Sc. thesis, Kiev, 45 pp.

Kulakovskaya O.P., Krotas R.A. 1961: [About the parasite Khawia sinensis Hsü, 1935 (Caryophyllaeidae, Cestoda) introduced to carp ponds of western regions of USSR from the FarEast.] Dokl. AN SSSR 137: 1253-1255. (In Russian.)

Li M.-M. 1964: A new genus and three new species of cestodes (Caryophyllaeidae) from Cyprinus carpio in China. Acta Zootaxon. Sin. 1: 355-366. (In Chinese, with English summary.)

Littlewood D.T.J., Curini-Galletti M., Herniou E.A. 2000: The interrelationships of Proseriata (Platyhelminthes: Seriata) flatworms tested with molecules and morphology. Mol. Phylogenet. Evol. 16: 449-466.

Littlewood D.T.J., Olson P.D. 2001: Small subunit rDNA and the Platyhelminthes: signal, noise, conflict and compromise.
In: D.T.J. Littlewood and R.A. Bray (Eds.), Interrelationships of the Platyhelminthes. Taylor and Francis, London, pp. 262-278.

Littlewood D.T.J., Waeschenbach A., Nikolov P.N. 2008: In search of mitochondrial markers for resolving the phylogeny of cyclophyllidean tapeworms (Platyhelminthes, Cestoda) - a test study with Davaineidae. Acta Parasitol. 53: 133-144.

Liu G., YanG W., Lin Y. 1995: Studies on the cestodes of fishes in Xiamen, Longhai and Fuzhou, Fujian Province \& a new species (Caryophyllaeidae) from Cyprinus carpio. J. Xiamen Univ. (Nat. Sci.) 34: 452-460. (In Chinese, with English summary.)

Mackiewicz J.S. 1972: Caryophyllidea (Cestoidea): a review. Exp. Parasitol. 31: 417-512.

Mackiewicz J.S. 1981a: Synoptic review of the Caryophyllidea (Cestoidea) of India, Pakistan and Nepal. Himalayan J. Sci. 1: $1-14$.

Mackiewicz J.S. 1981b: Caryophyllidea (Cestoidea): evolution and classification. Adv. Parasitol. 19: 139-206.

Mackiewicz J.S. 1994: Order Caryophyllidea van Beneden in Carus, 1863. In: L.F. Khalil, A. Jones and R.A. Bray (Eds.), Keys to the Cestode Parasites of Vertebrates. CAB International, Wallingford, pp. 21-43.

MACKIEWICZ J.S. 2003: Caryophyllidea (Cestoidea): molecules, morphology and evolution. Acta Parasitol. 48: 143-154.

Markevich A.P. 1951: [Parasite fauna of freshwater fish of the Ukraine SSR.] Izdatelstvo Akademii Nauk Ukraine SSR, Kiev, 376 pp. (In Russian.)

Mikailov T.K. 1975: [Parasites of Fishes in Water Bodies of Azerbaidzhan (Systematics, Dynamics, Origin)]. Publ. House ELM, Baku, 300 pp. (In Russian.)

MolnÁr K. 1968: Bothriocephalus phoxini sp. n. (Cestoda, Pseudophyllidea) from Phoxinus phoxinus L. Folia Parasitol. 14: 83-86.

MolnÁR K. 1977: On the synonyms of Bothriocephalus acheilognathi Yamaguti, 1934. Parasitol. Hung. 10: 61-62.

MoRAVEC F. 1984: First record of the cestode Khawia baltica Szidat, 1941 in Czechoslovakia. Folia Parasitol. 31: 373-374.

Morley N.J., Hoole D. 1995: Ultrastructural studies on the hostparasite interface between Khawia sinensis (Cestoda: Caryophyllidea) and carp Cyprinus carpio. Dis. Aquat. Org. 23: 93-99.

Morley N.J., Hoole D. 1997: The in vitro effect of Khawia sinensis on leukocyte activity in carp (Cyprinus carpio). J. Helminthol. 71: 47-52.

Musselius V., Ivanova N., Laptev V., Apazidi L. 1963: [Khawia sinensis Hsü, 1935 of carp.] Ribov. Ribolovstvo 3: 25-27. (In Russian.)

Olson P.D., Cribb T.H., Tkach V.V., Bray R.A., Littlewood D.T.J. 2003: Phylogeny and classification of the Digenea (Platyhelminthes: Trematoda). Int. J. Parasitol. 33: 733-755.

Olson P.D., Littlewood D.TJ., Bray R.A., Mariaux J. 2001: Interrelationships and evolution of the tapeworms (Platyhelminthes: Cestoda). Mol. Phylogenet. Evol. 19: 443-467.

Olson P.D., Scholz T., Poddubnaya L.G., Littlewood D.T.J. 2008: On the derived position of Archigetes and the early evolution of the tapeworms (Platyhelminthes: Cestoda). J. Parasitol. 94: 898-904.

Oros M., Hanzeloví V. 2007: The morphology and systematic status of Khawia rossittensis (Szidat, 1937) and K. parva (Zmeev, 1936) (Cestoda: Caryophyllidea), parasites of cyprinid fishes. Syst. Parasitol. 68: 129-136.

Oros M., Hanzelová V., Scholz T. 2009: Tapeworm Khawia sinensis: review of the introduction and subsequent decline of a pathogen of carp, Cyprinus carpio. Vet. Parasitol. 164: 217222.

Oros M., Hanzelová V., Scholz T., Mackiewicz J.S. 2008: Phylogenetic relationships of the monozoic tapeworms (Eucestoda: 
Caryophyllidea) inferred from morphological characters. Syst. Parasitol. 70: 1-14.

Oros M., Scholz T., Hanzelová V., Mackiewicz J.S. 2010: Scolex morphology of monozoic cestodes (Caryophyllidea) from the Palaearctic Region: a useful tool for species identification. Folia Parasitol. 57: 37-46.

Orosová M., Marec F., Oros M., Xi B.-W., Scholz T. 2010: A chromosome study and localization of $18 \mathrm{~S}$ rDNA in Khawia saurogobii (Cestoda: Caryophyllidea). Parasitol. Res. 103: 587-593.

PAGE R.D.M. 1996: TREEVIEW: an application to display phylogenetic trees on personal computers. Comp. Appl. Biosci. 12: 357-358.

Poddubnaya L.G., Karen J. 2003: Parasitation of Sevan khramulya (Varicorhinus capoëta sevangi) by the caryophyllidean cestode Khawia armeniaca. Int. Seminar "Current Issues of Conservation and Wise Use of Wetlands and Wetland Biodiversity in the European New Independent States", 15-19 September 2003, Sevan, Armenia. Abstracts of papers, p. 45. (In Russian.)

Pool D.W. 1987: A note on the synonymy of Bothriocephalus acheilognathi Yamaguti, 1934, B. aegyptiacus Ryšavý and Moravec, 1975 and B. kivuensis Baer and Fain, 1958. Parasitol. Res. 73: $146-150$.

Pool D.W., Снuвв J.C. 1985: A critical scanning electron microscope study of the scolex of Bothriocephalus acheilognathi Yamaguti, 1934, with a review of the taxonomic history of the genus Bothriocephalus parasitizing cyprinid fishes. Syst. Parasitol. 7: 199-211.

Popov T.A. 1924: The anatomical structure of Caryophyllaeus armeniacus N. Cholodkowsky, 1915, and its position in the system. Trudy Trop. Inst. Arm., Yerevan, 1: 67-73.

Protasova E.P., Kuperman B.I., Roitman V.A., Poddubnaya L.G. 1990: [Caryophyllid Tapeworms of the Fauna of USSR.] Nauka, Moscow, 237 pp. (In Russian.)

Rahemo Z.I.F., Al-Kalak S.N. 1993: A new record of a caryophyllaeid cestode, Khawia armeniaca from Iraq. Acta Parasitol. Turc. 17: 74-78.

Rahemo Z.I.F., Mohammad S.A. 2002: Khawia barbi sp. n. (Cestoda: Caryophyllidae) from the common freshwater fish, Barbus luteus from river Tigris, Mosul, Iraq. Riv. Parassitol. 19: 189-192.

Rota-Stabelli O., Yang Z., Telford M.J. 2009: MtZoa: a general mitochondrial amino acid substitutions model for animal evolutionary studies. Mol. Phylogenet. Evol. 52: 268-272.

Rydlo M. 1985: Die Bedeutung von Parasiten als Indikator für die Ernährungsweise des Wirtes am Beispiel von Seelaube (Chalcalburnus chalcoides mento), Rusnase (Vimba vimba elongata) und Seesaibling (Salvelinus alpinus). Öster. Fisch. 38: 279-283.

Schaeffner B.C., Jirkư M., Mahmoud Z.N., Scholz T. 2011: Revision of Wenyonia (Cestoda: Caryophyllidea) from Synodontis catfish in Africa. Syst. Parasitol. 73: 83-107.

SchmidT G.D. 1986: CRC Handbook of Tapeworm Identification. CRC Press, Boca Raton, Florida, 675 pp.

Scholz T. 1989: Amphilinida and Cestoda, parasites of fish in Czechoslovakia. Acta. Sci. Nat. Brno 23: 1-56.

Scholz T. 1991a: Development of Khawia sinensis Hsü, 1935 (Cestoda: Caryophyllidea) in the definitive host. Folia Parasitol. 38: 225-234.

Scholz T. 1991b: Early development of Khawia sinensis Hsü, 1935 (Cestoda: Caryophyllidea). Folia Parasitol. 38: 133-142.

Scholz T. 1993: On the development of Khawia baltica Szidat, 1942 (Cestoda, Lytocestidae), a parasite of tench, Tinca tinca (L.). Folia Parasitol. 40: 99-104.
Scholz T., Binh T.T., Dezfuli D.S. 2011: Khawia japonensis (Cestoda: Caryophyllidea): another invasive parasite of carp (Cyprinus carpio) imported to Europe. J. Fish Dis. (In press.)

Scholz T., Hanzelová V. 1998: Tapeworms of the Genus Proteocephalus Weinland, 1858 (Cestoda: Proteocephalidae), Parasites of Fishes in Europe. Studie AV ČR, No. 2/98, Academia, Praha, 119 pp.

Scholz T., Shimazu T., Olson P.D., Nagasawa K. 2001: Caryophyllidean tapeworms (Platyhelminthes: Eucestoda) from freshwater fishes in Japan. Folia Parasitol. 48: 275-288.

Scholz T., ŠPeTA V., ZAJí̌EK J. 1990: Life history of the tapeworm Khawia sinensis Hsü, 1935, a carp parasite, in the pond Dražský Skaličany near Blatná, Czechoslovakia. Acta Vet. Brno 59: 51-63.

ShCHERBan M.P. 1965: [Cestode Infections of Carp.] Izdatelstvo Urozhai, Kiev. (In Russian.)

Shulman S.S. 1958: [Zoogeographical analysis of parasites of freshwater fish of the USSR.] In: V.A. Dogiel, G.K. Petrushevskii and Yu.I. Polyanski (Eds.), Basic Problems of the Parasitology of Fish. Izdatelstvo Leningradskogo Universiteta, Leningrad, pp. 184-230. (In Russian.)

Smyth J.D., McManus P. 1988: The Physiology and Biochemistry of Cestodes. Cambridge University Press, Cambridge, 398 pp.

Swofford D.L. 2002: PAUP*. Phylogenetic Analysis Using Parsimony (*and Other Methods). Sinauer Associates, Sunderland, MA.

SzIDAT L. 1937: Über einige neue Caryophyllaeiden aus ostpreussischen Fischen. Z. Parasitenkd. 9: 771-786.

SzIDAT L. 1941: Über die Caryophyllaeiden-Gattung Khawia H. F. Hsü, 1935 und eine neue Art dieser Gattung, Khawia baltica $\mathrm{n}$. spec. Z. Parasitenkd. 12: 120-132.

Wardle R.A., McLeod J.A. 1952: The Zoology of Tapeworms. The University of Minnesota Press, Minneapolis, $750 \mathrm{pp}$.

Weirowski F. 1979: Die wirtschaftliche Bedeutung und Verbreitung von Khawia sinensis Hsü, 1935 in der Karpfenproduktion der DDR. Z. Binnenfisch. DDR 26: 373-376.

Williams H.H., Jones A. 1994: Parasitic Worms of Fishes. Taylor \& Francis, London \& Bristol, 593 pp.

Williams J.S., Gibson D.I., Sadighian A. 1980: Some helminth parasites of Iranian freshwater fishes. J. Nat. Hist. 14: 685-699.

Xi B.-W., Oros M., Wang G.-T., Wu S.-G., Gao D., Nie P. 2009a: Khawia saurogobii n. sp. (Cestoda: Caryophyllidea) from freshwater fish Saurogobio spp. (Cyprinidae) in China. J. Parasitol. 95: 965-970.

Xi B.-W., Wang G.-T., Wu S.-G., Gao D., Nie P. 2009b: New record of genus Atractolytocestus in China with redescription of A. sagittatus (Cestoda, Caryophyllidea) from Cyprinus carpio. Acta Zootaxon. Sin. 34: 407-410.

XIA X., XIE Z. 2001: DAMBE: Data analysis in molecular biology and evolution. J. Hered. 92: 371-373.

Xia X., Xie Z., Salemi M., Chen L., Wang Y. 2003: An index of substitution saturation and its application. Mol. Phylogenet. Evol. 26: 1-7.

YAmAGUTI S. 1934: Studies on the helminth fauna of Japan. Part 4. Cestodes of fishes. Jpn. J. Zool. 6: 1-112.

Yamaguti S. 1959: Systema Helminthum, Vol. II. The Cestodes of Vertebrates. Keigaku Publishing House, Tokyo, 860 pp.

YANG W. 2007: A list of fish cestodes reported from China. Syst. Parasitol. 68: 71-78.

ZMeEv G.J. 1936: [Flukes and tapeworms of fish of the Amur River.] Parazitol. Sb. Zool. Inst. Akad. Nauk SSSR 6: 423-435. (In Russian.)

Accepted 7 June 2011 